\title{
Reserve Growth of Oil and Gas Fields-Investigations and Applications
}

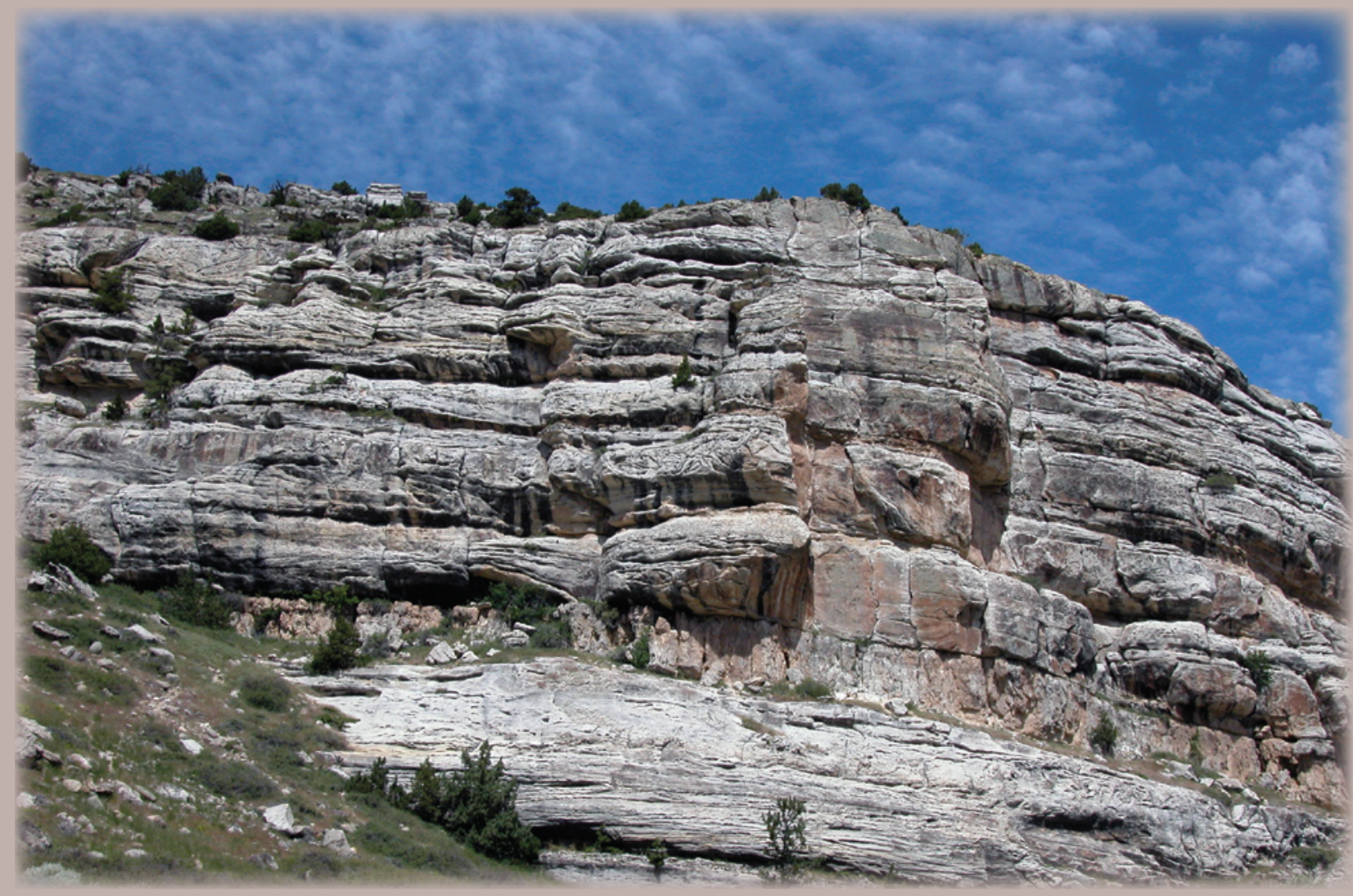

Scientific Investigations Report 2013-5063

U.S. Department of the Interior

U.S. Geological Survey 
COVER. Outcrop of Tensleep Sandstone in Sinks Canyon, Wyoming, showing the complex compartmentalization commonly observed in this important eolian oil and gas reservoir (photo taken by Christopher J. Schenk, U.S, Geological Survey, in 2004). 


\section{Reserve Growth of Oil and Gas Fields- Investigations and Applications}

By Troy A. Cook

Scientific Investigations Report 2013-5063 


\title{
U.S. Department of the Interior SALLY JEWELL, Secretary
}

\section{U.S. Geological Survey Suzette M. Kimball, Acting Director}

\author{
U.S. Geological Survey, Reston, Virginia: 2013
}

For more information on the USGS - the Federal source for science about the Earth, its natural and living resources, natural hazards, and the environment, visit http://www.usgs.gov or call 1-888-ASK-USGS.

For an overview of USGS information products, including maps, imagery, and publications, visit http://www.usgs.gov/pubprod

To order this and other USGS information products, visit http://store.usgs.gov

Any use of trade, firm, or product names is for descriptive purposes only and does not imply endorsement by the U.S. Government.

Although this information product, for the most part, is in the public domain, it also may contain copyrighted materials as noted in the text. Permission to reproduce copyrighted items must be secured from the copyright owner.

Suggested citation:

Cook, T.A., 2013, Reserve growth of oil and gas fields - Investigations and applications: U.S. Geological Survey Scientific Investigations Report 2013-5063, 29 p., http://pubs.usgs.gov/sir/2013/5063/. 


\section{Contents}

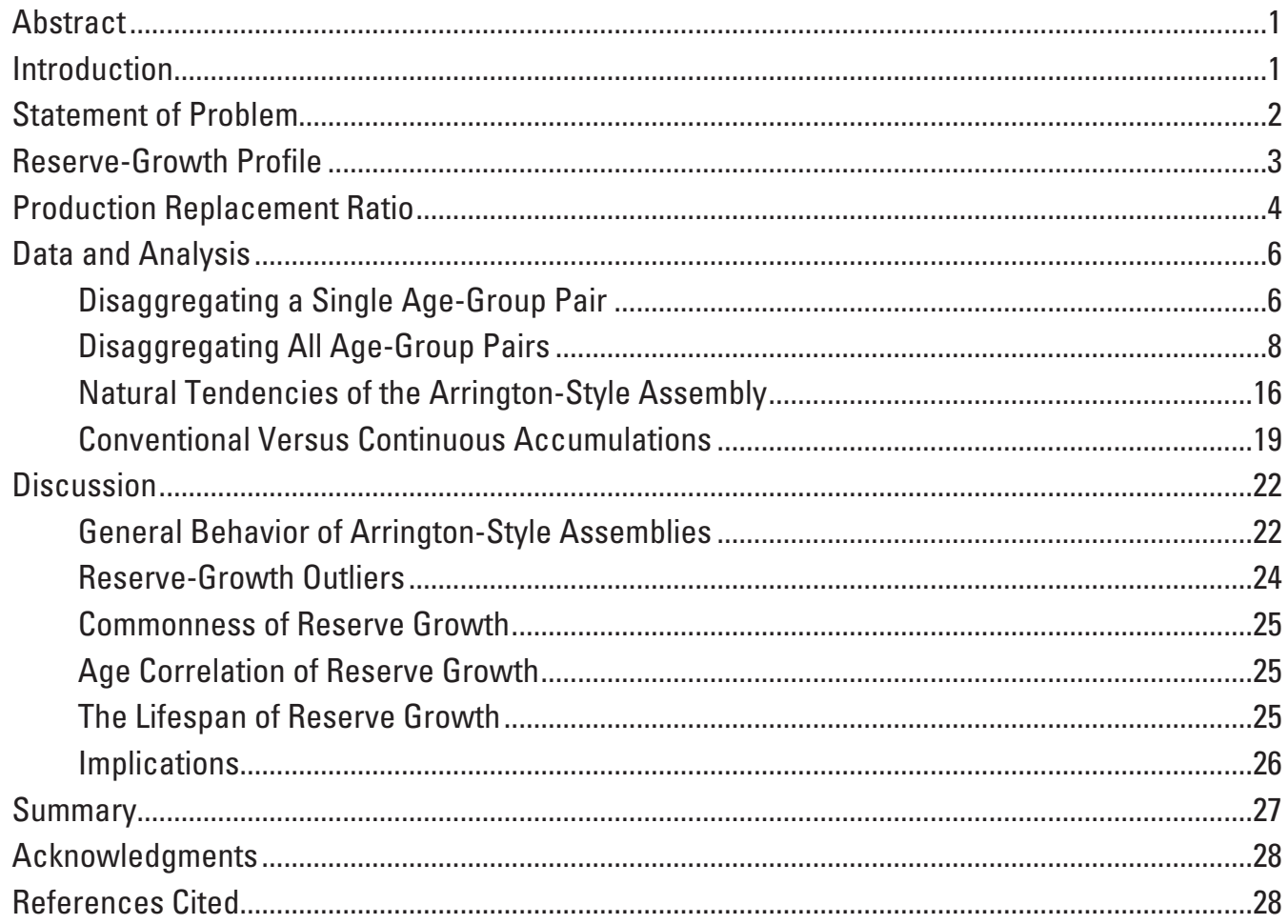

\section{Figures}

1 Coalinga oil field cumulative production, estimated ultimate recovery, and production-replacement ratio (PRR) with respect to time................................................

2 Mount Poso oil field cumulative production, estimated ultimate recovery, and production replacement ratio (PRR) with respect to time ................................................5

3 Estimated known recoverable oil for conventional oil fields 61 years after discovery year.

4 Average conventional oil field size, volume changes, and field counts for all age groups

5 Average reserve growth in conventional oil fields per field per age-group pair including percentage of fields where cumulative production equals estimated known recovery.

6 Number and size of oil fields required to generate 75 percent of gross field growth in each age-group pair

7 Volumetric contribution of gross reserve growth for major and nonmajor conventional oil fields in each age group.

8 Percentage of gross reserve growth and total known recovery of the single largest growing oil field in each age-group pair..........................................................................11

9. Gross reserve growth of five largest growing oil fields in each age group.....................12

10. Field counts and gross reserve growth of major oil fields...........................................12

11. Field counts and net reserve growth of nonmajor oil fields ........................................13 
12. Net reserve growth from San Joaquin Basin oil fields and volumetrically weighted reserve growth by American Petroleum Institute (API) oil gravity .................................14

13. Field counts and gross reserve growth of major gas fields ............................................14

14. Field counts and net reserve growth of nonmajor gas fields........................................15

15. Gross reserve growth of oil from a few fields across multiple age-group pairs. ............15

16. Example of the interaction of nine nonlinear declines.................................................18

17. Annual fractional change of nine nonlinear declines and dependency of that answer on smallest decline

18. Fractional effect on group behavior caused by the difference between group behavior and the single smallest decline within the group 19

19. Discovery-year groups with early histories of estimated ultimate recovery through time

20. Annual growth factors for top five oil fields in each age-group pair versus all others

21. Annual growth factors for top five gas fields in each age-group pair versus all others

22. Example of consistent reserve growth in an actual billion-barrel oil field in Texas .......21

23. Differences in cumulative growth curve results based on a single annual growth factor change

24. Differences in cumulative growth curve results based on the removal of all fields with no changes in reserve growth in that age-group pair.

\section{Tables}

1. Mount Poso oil field production replacement ratio (PRR) calculation over two different time spans

2. Known petroleum volumes (KPVs) for conterminous United States, excluding Federal offshore and continuous fields......................................................................................

3. Single age-group sequence of known recovery change and related calculations ........17

4. Example of an annual growth factor calculation that includes all fields ........................22

5. Example of an annual growth factor with a single field removed from the calculation

\section{Initialisms}

AGF annual growth factor

API American Petroleum Institute

CGF cumulative growth function

EIA Energy Information Agency

EPCA Environmental Policy and Conservation Act

GOR gas to oil ratio

OGIFF Oil and Gas Integrated Field File

PRR production replacement ratio 


\title{
Reserve Growth of Oil and Gas Fields-Investigations and Applications
}

\author{
By Troy A. Cook
}

\section{Abstract}

The reserve growth of fields has been a topic for ongoing discussion for over half a century and will continue to be studied well into the future. This is due to the expected size of the volumetric contribution of reserve growth to the future supply of oil and natural gas. Understanding past methods of estimating future volumes based on the data assembly methods that have been used can lead to a better understanding of their applicability. The statistical nature of past methods and the (1) possible high level of dependency on a limited number of fields, (2) assumption of an age-based correlation with effective reserve growth, and (3) assumption of long-lived and more common than not reserve growth, may be improved by employing a more geologically based approach.

\section{Introduction}

Reserve growth, inferred reserves, field appreciation, ultimate recovery appreciation, and field growth are all terms that have been used to refer to changes in the estimated ultimate size of an oil and gas field or an aggregation of fields. The term "reserve growth" will be used in this study. The term "field" will be used to refer to an oil and gas producing entity based on a collection of oil and gas pools of varying depths, sizes, and geologic characteristics. The estimated ultimate size of a field's recoverable volume changes with respect to time, additions and extensions of the field, new pools discovered within the field, improvements in recovery technology, and the level of development of a field. It should be noted that fields can also have their estimated ultimate size revised downward as well.

Comments on reserve growth have been made at the field, play, basin, country, and world level, and various individuals and organizations have recognized, described, and estimated reserve growth for nearly 50 years. The importance of understanding and estimating reserve growth is critical to future reserve and resource appraisals because its magnitude can equal or exceed the volumes of future discoveries. If reserve growth of existing fields is not taken into account, the result would be a continual underestimation of the current inventory of oil and natural gas resources available for development.

This study of reserve growth was completed as part of an ongoing U.S. Geological Survey (USGS) project to investigate the causes and behavior of reserve growth that lead to better estimates of future petroleum potential. As part of this analysis of reserve growth, an additional component - the production replacement ratio (PRR) of reserve growth - was created. The PRR focuses on a profile of reserve growth that is independent of volume or percentage measures and is capable of identifying fields displaying the reserve-growth profile at any particular point in time or across the entire history of a field. Once the PRR was conceptually formulated, it was tested using field-level reserve-growth information of the United States contained within the Nehring Associates (NRG) database (NRG Associates, 2008).

In addition to identifying this profile of reserve growth, an analysis of the Arrington-style age-based methods (Arrington, 1960; hereafter referred to as Arrington-style methods) was undertaken to better understand the consequences of temporal aggregations and to determine if the implications from these aggregations are valid. This analysis uncovered a high level of volumetric dependency on a small number of fields revealing a bimodal population within the field growth data. Initially a field's estimated known recovery can grow (or shrink) as well performance establishes reservoir behavior, new pools are tested, and the delineation of the field continues with early field development. This early reservegrowth (or shrink) effect then combines with a separate and near-linear growth mechanism in a minority of fields. These two effects, early and late, are generally combined to provide an overall impression of reserve growth.

Understanding how these mechanisms interact is important when constructing a method to estimate future reserve growth. Field reserve growth in the past has been a significant and consistent volumetric contributor to the total volume inventory in the United States and is expected to have the same effect at the international level.

No systematic attempt was made in this study to explain or find definitive geological or engineering significance that is causally related to reserve growth at the field level, although general comments on these topics are discussed. This study utilizes the information from approximately 
15,000 conventional oil and gas fields spanning 24 years of known recovery estimates within the NRG Associates (2008) database to draw conclusions. These conclusions may not be valid beyond the bounds of this particular dataset; however, a review of other reserve-growth studies shows similar patterns, and the work demonstrated here might be appropriate for a similar analysis in other groups of fields.

\section{Statement of Problem}

It has been widely recognized that Arrington (1960) was the first to use an age-based "running rate of growth with time with a constantly changing group of fields" method to estimate reserve growth, which he applied to the oil fields of Carter Oil Co. in the 1940s. Of note in Arrington's examples is that his "running rate of growth" calculation covered 27 years, and he stated "This is a valuable tool for management in helping them learn new facts which might not otherwise be available for 5 or 10 years" (Arrington, 1960, p. 134). He also listed the limitations of the method and cautioned that studies of this type can be used improperly, further writing that (1) the results could not be used on any group of fields except those from which they were derived; (2) the results could not be applied to a smaller number of statistics than the group from which they were derived (never to a single field); and (3) the entire construction was a probability concept.

This "running rate of growth" method can be described as the volume changes between sequential sums being quantified as a percentage change between sums. When the percent changes in ultimate field recovery are plotted with respect to time, this manner of assembling the data leads to a decline that resembles a natural decay function.

Hubbert (1967) used a slightly different method to calculate reserve growth while still maintaining the age relation to the size of the reserve growth. This method involved average cumulative growth curves derived from past changes in estimates of American Petroleum Institute (API)-American Gas Association ultimate oil and gas recovery with respect to the time since the fields were discovered. Unlike Arrington's (1960) concept, Hubbert fit his function to the cumulative growth through time and incorporated an asymptote into this equation to calculate the growth from initial discovery size at any point in time. This distinction, to limit both the total length of growth and any ultimate sizes derived from it, becomes more critical as reserve-growth estimates are made over long time frames. The USGS incorporated this method into its domestic assessments starting in 1975 (Mast and Dingler, 1975) and used it with slight modifications afterwards.

A variation of the age-based growth concept was described by Attanasi and Root (1994) through the use of a monotone growth function. This method is similar to the Arrington-style of assembling the data but utilizes a custom algorithm to fit the running rate of growth data. Attanasi and Root (1994) also identified subgroups within the data labeled as "outliers." These outliers were characterized as large heavyoil fields and old low-permeability gas fields whose reserve growth was six times faster than the common fields. These fields were located by comparing an individual field to an initial regression of all the data and labeling those outside that average regression "outliers." This average initial regression was based on field ultimate-recovery-size data from 1977 to 1991.

The monotone function became the method for calculating reserve-growth projections for USGS domestic assessments in 1995 (Gautier and others, 1996) and international assessments (Schmoker and Klett, 2000). Schmoker and Klett (2000) enumerated "formidable" difficulties in estimating potential future reserve growth. Included in their analysis was documentation of their reasoning for how this method may overestimate or underestimate the actual reserve growth. Based on the potential size of this growth, as well as the uncertainty in its volumetric size, their conclusion was that no world-level assessment could be complete without providing a reserve-growth estimate.

Two other age-based methods have also been used to project potential growth after the publication of the USGS world energy assessment results (U.S. Geological Survey World Energy Assessment Team, 2000). One is the modified Arrington approach utilized by Verma (2005) for the United States, Verma and Henry (2004) for Saskatchewan, Verma and Ulmishek (2003) for the West Siberian Basin, and Verma and others (2001) for the Volga-Ural Province. This method differs from the original Arrington method primarily by making a best-fit to the cumulative of the running rate of growth rather than the running rate itself. It is similar to Hubbert's (1967) method in that growth has been captured in a single equation best-fit to the cumulative growth curve. It is dissimilar in that it does not incorporate an asymptote in the equation. This bestfit to the cumulative curve is also similar to the hyperbolic fit used to estimate potential growth on onshore Federal lands by the Environmental Policy and Conservation Act report (EPCA) (U.S. Departments of Interior, Agriculture, and Energy, 2008). It was used on relatively small groups of data when compared to some of the national-scale studies completed previously and explicitly extends reserve-growth estimates to three centuries. The combination of this timespan and a hyperbolic fit also implies that reserve growth is seemingly endless and may even be projected beyond the three centuries already used.

After the Attanasi and Root (1994) results were published, concerns were raised about the information and conclusions, as well as suggestions that additional study was warranted. The best example available of these concerns within a single study was given by Morehouse (1997) of the Energy Information Agency (EIA) who posed questions and presented comments that directly influenced the direction of the present investigation. Following Morehouse (1997) these concerns are as follows: 
1. Multiple types of differently formulated but similar curves could be fit to the existing data with "little objective assurance that the results are either significantly unique or even appropriate."

2. Due to inherent data limitations, including a high variance among what was considered "good" data, statistical smoothing was required to render the data suitable for analytical use.

3. Causal relations, particularly those of interest to a geologist, were "deeply buried" within the datasets with no apparent ability to subset the data appropriately.

4. Only a single study had been done that included both the time component of reserve growth and drilling activity assumed necessary to create that growth.

5. There are questions related to data applicability because of the perceived differences between large and small fields. This comment appears to extend beyond the outliers noticed in the work of Attanasi and Root (1994) to the size of fields in general.

Field groups of the North Sea were analyzed in a study completed by Sem and Ellerman (1999) that was designed to examine reserve growth with respect to location, size, and discovery date in different sectors of the North Sea. This study is also one of the few to include an estimate of the total production generated from that reserve growth. As part of their conclusions, Sem and Ellerman (1999) expressed surprise that growth did not appear as expected in certain sizes of fields.

Klett (2003) in an investigation of reserve-growth models, observed that a list of assumptions was made during nearly all projections of reserve growth. He also (1) summarized models of reserve growth linked to closely related factors, such as economic conditions, geologic characteristics, and engineering practices and (2) suggested that reservegrowth models might be improved, stating "The relative importance of reservoir properties, trapping mechanisms, oil and gas characteristics, and other geological factors, oil and gas recoverability, commodity price, drilling activity, development of new technologies, and development of infrastructure, such as platforms and pipelines, must be identified to fully characterize and quantify the controls on reserve growth. Such studies can best be done in those few areas of the world where development is advanced and fields, resources, technology, and data are abundant."

Tennyson (2005) studied some of the California oil fields originally labeled as outliers by Attanasi and Root (1994) and appeared to have concerns similar to item number 1 listed above, stating that "Without at least a qualitative understanding of the factors responsible for the late growth in these old fields, future assessments risk continued imprecise prediction of additions to reserves in this important region, along with perhaps undue influence on other regions stemming from failure to isolate factors peculiar to California"
(Tennyson, 2005, p. 1). Although the comment itself is specific to the California oil field outliers, it is possible that the same concept might apply to other areas as well.

The most common assumption in studies of reserve growth is that there is an overall age dependency allowing sequential projections of the aggregate data. This assumption, which could also be referred to as "the future will look like the past," influences not only how reserve growth is thought about, studied, and tested, but how its effects are extrapolated.

A more recent concept is that of reserve-growth "outliers," a term used to describe fields that do not behave in an expected manner. Reasonable questions have been raised as to the nature and effect of these "outliers" and their relation to the majority of fields. A study of these outliers has led to comments questioning the very methods used to identify these particular field groups in the first place. The present study was designed to investigate these types of questions and to determine what, if any, implications or guidance could be derived from the results, including (1) defining a new profile-based definition of reserve growth, (2) providing individual fieldlevel examples, and (3) an in-depth examination of the way reserve-growth information is aggregated.

\section{Reserve-Growth Profile}

Reserve growth is generally measured in terms of volume or percentages. To some extent the Arrington-style calculation of "running rate of growth" is a combination of both. The problem with these types of comparisons is that they are frame-of-reference specific and make it difficult to compare results relative to one another. A volumetric comparison or ranking will not yield the same result as a percentage comparison or ranking. For example, assume that (1) there are two oil fields, one with an estimated ultimate recovery of 100 million barrels and the other with 1 million barrels; and (2) the larger field grows by 1 million barrels over a 10-year time span (1-percent growth) and the other by 0.1 million barrels over the same time span (10-percent growth). Either field can now demonstrate larger reserve growth than the other.

In order to minimize this type of comparative confusion, a signature or profile of reserve growth was created and is referred to in this study as the production replacement ratio (PRR). Sem and Ellerman (1999) touched briefly on the basis for this type of reserve-growth signature by stating "When reserves are appreciating at $2-3 \%$ of total reserves and depletion is occurring at similar rates, production is being replaced. The result is a more or less constant level of inventory." This concept of Sem and Ellerman (1999) is referred to in this study as the stable-inventory profile of reserve growth.

The understanding of reserve growth can be improved by incorporating this type of age- and size-independent profile. The profile can be used to locate fields displaying present-day or past reserve-growth behavior and compare those fields with 
other growing or nongrowing fields regardless of field size and age. The comparison between consistently growing fields with all others will allow a detailed examination and quantification of the actual causes of reserve growth.

\section{Production Replacement Ratio}

Production replacement ratio is the means by which the stable-inventory profile can be identified and the strength of the profile quantified. It can be described as the difference in estimated ultimate field size between any two points in time divided by the cumulative production over that same period of time. If P1 equals cumulative production at time 1, P2 equals cumulative production at time $2, \mathrm{KR} 1$ equals the estimated ultimate field size at time 1, and KR2 equals the estimated ultimate field size at time 2 , then the PRR $=(\mathrm{KR} 2-\mathrm{KR} 1) /$ (P2-P1). The PRR is dimensionless with respect to absolute barrels and equal to 1 when a field has achieved the stableinventory-profile condition described by Sem and Ellerman (1999). This profile of $P R R=1$, although sustainable over long periods of time, cannot be infinitely maintained, because all fields have an upper limit bounded by their geology. As the PRR decreases toward 0, progressively smaller amounts of production are being replaced by growth in estimated ultimate field size. A PRR of 0 means that reserve growth of the field is zero. When PRR is negative, the field is actually shrinking in ultimate size for every unit of oil or gas produced. The PRR can be calculated over the entire history of a field or for just a portion of it. This subdividing of the field's lifespan can be used to determine the time frame when changes in reservegrowth behavior took place or if reserve growth for a field has ceased.

Described another way, a strong reserve-growth profile exists when the known recoverable size of a field remains stable with respect to gains in cumulative production over the same period of time. A field's known recoverable size is the sum of its cumulative production and estimated remaining recoverable volumes over the entire life of the field. This change in known recoverable size with respect to time is the most common measure of reserve growth. Figure 1 is an example of this effect. The Coalinga oil field in the San Joaquin Basin of California had produced approximately 406,059,000 barrels by 1945 and 906,373,000 barrels by 2005. During that same period of time, estimates of its known recovery had grown from 510,009,000 barrels to 969,890,000 barrels. The PRR for this oilfield spanning the referenced time frame is $(969,890,000-510,009,000) /(906,373,000$ $406,059,000)=0.92$. For each barrel of oil produced across

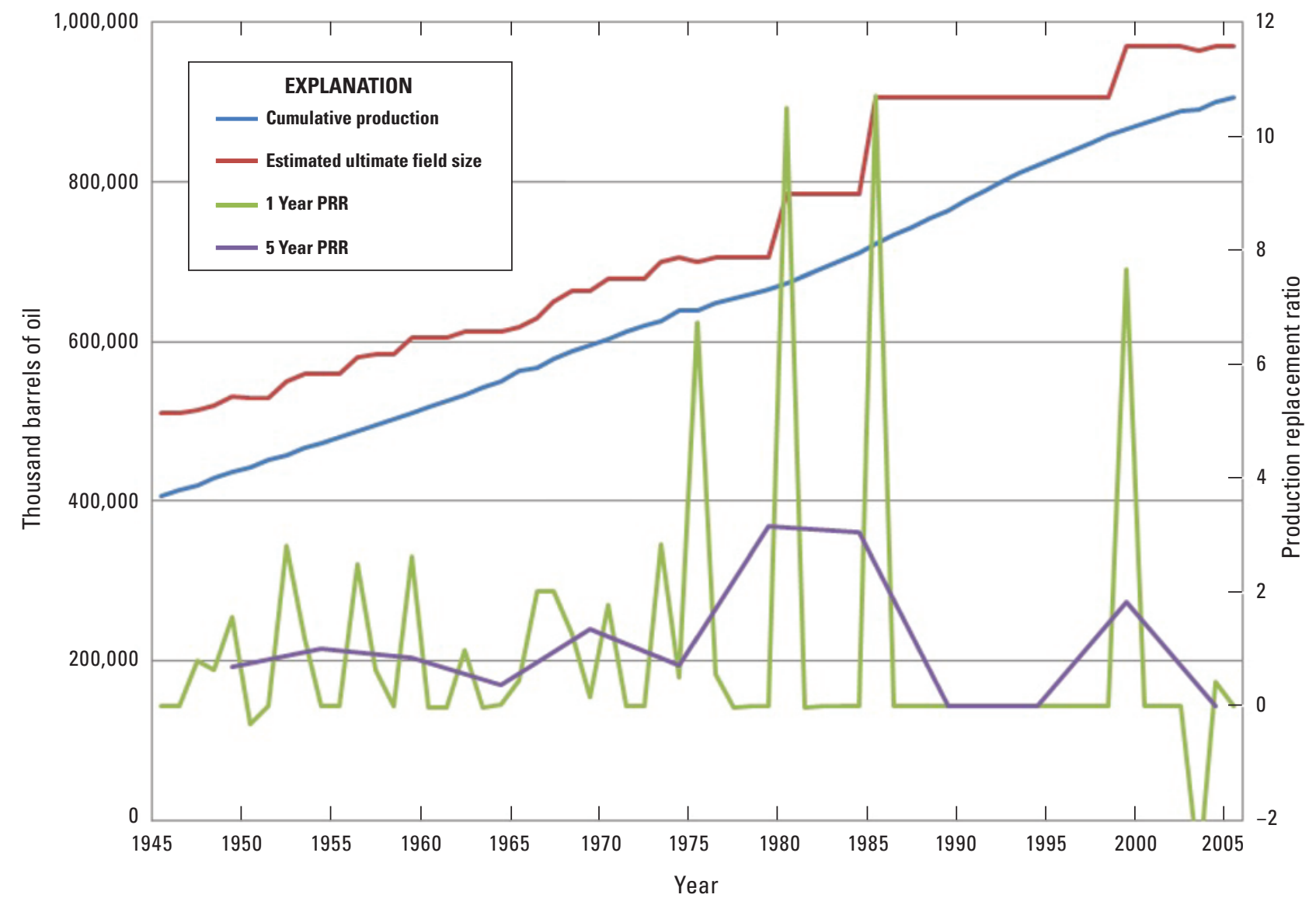

Figure 1. Coalinga oil field cumulative production, estimated ultimate recovery, and production replacement ratio (PRR) with respect to time. Unpublished data courtesy of M.E. Tennyson, U.S. Geological Survey. 
this time frame, 0.92 barrel was "discovered" in the field and added to its known recovery. Coalinga is therefore a relatively strong example of reserve growth at the field level by this measure. PRRs are included in figure 1 for single-year changes as well as 5 -year changes for reference.

Figure 2 shows the Mount Poso oil field in the San Joaquin Basin of California in the same format as figure 1. Table 1 demonstrates how using the PRR over intermediate periods of time can be used to identify growth periods during the life of a given field. PRRs for this field are also included in figure 2 for single-year changes as well as 5-year changes.

Using these two fields as examples, it would be reasonable to state that both fields have demonstrated strong reserve growth in the past. However, Coalinga was able to maintain that growth consistently through the year 1990, but Mount Poso did not. Since 1985 Mount Poso has shown a profile related to reserve shrinkage rather than growth, whereas Coalinga has shown a reduction in its reserve-growth profile since 1990. The current PRR profile does not preclude either field from going through another growth period, but based on their PRR profiles, both fields appear to be tapering off from past high-growth periods. Factors that might activate another round of growth are the same factors that are assumed to drive reserve growth in the first place, such as better economics, new production technologies, or revisions and extensions (field size or new pools) of the field. These possible futuregrowth scenarios are unlikely to be predictable in a statistical manner at the field level without substantial geologic or engineering insight.

One characteristic of note is that the PRR is 0 for all fields prior to the onset of production. Unlike an Arringtonstyle of assembly based on discovery date, the PRR cannot identify growth until initial production and field-size estimates are established. As has been noted by other authors (for example, Forbes and Zampelli, 2009; Verma and Ulmishek, 2003), the results of an Arrington-style of assembly are different and are sensitive to the starting position of the data assembly.

The advantages of including this profile of reserve growth with other measures of volume and percentage can be substantial. The PRR identifies the historical profile of growth irrespective of field percentage or volume growth, overall field size, or age. It can be tailored to the length and specificity of the production and known recoverability information and can be used to identify anomalous fields for a more detailed investigation of why reserve growth did, or did not, happen.

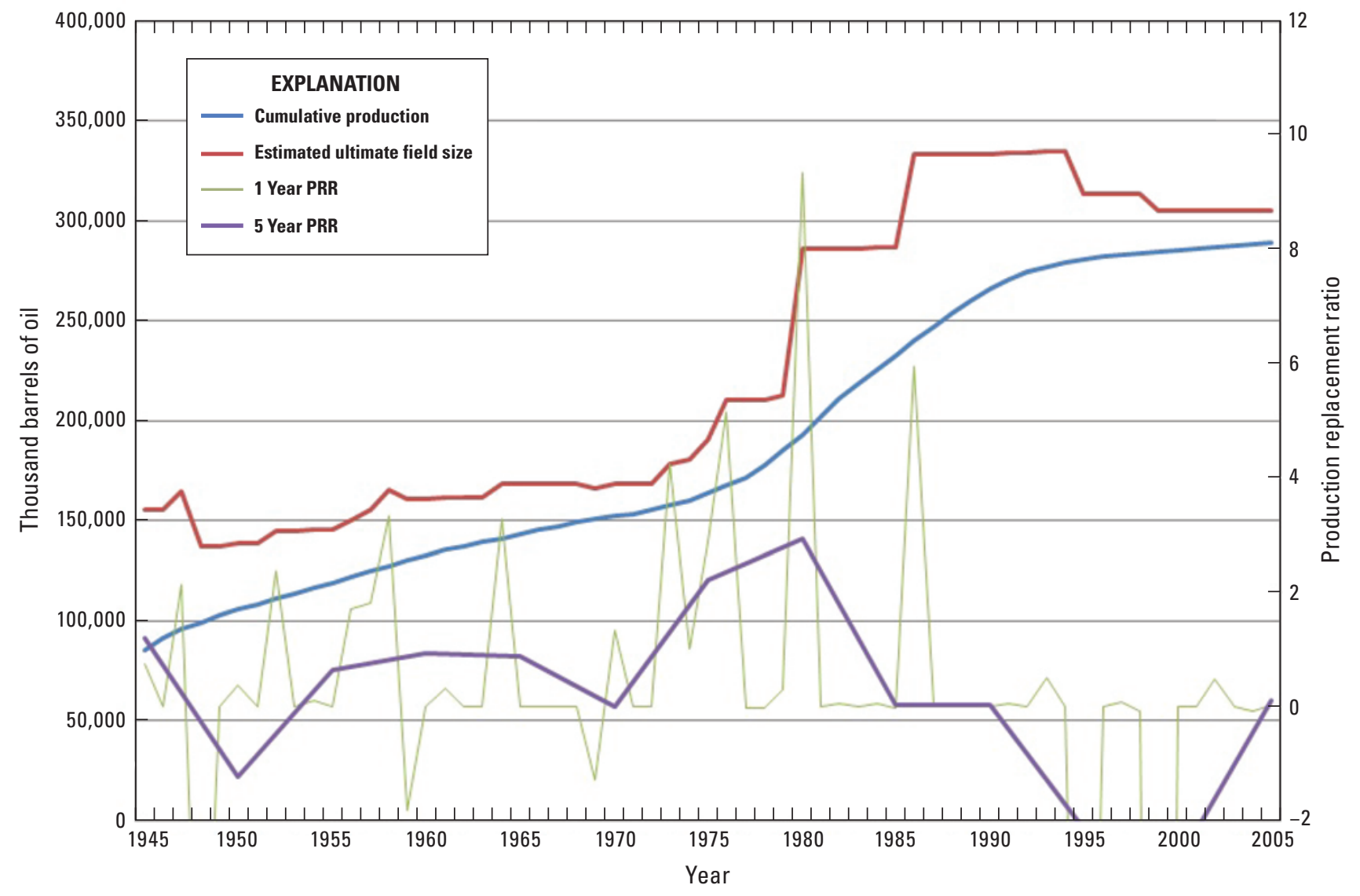

Figure 2. Mount Poso oil field cumulative production, estimated ultimate recovery, and production replacement ratio (PRR) with respect to time. Unpublished data courtesy of M.E. Tennyson, U.S. Geological Survey. 
Table 1. Mount Poso oil field production replacement ratio (PRR) calculation over two different time spans.

\begin{tabular}{cccc}
\hline Year & $\begin{array}{c}\text { Cumulative oil } \\
\text { production }\end{array}$ & $\begin{array}{c}\text { Ultimate oil } \\
\text { recovery estimate }\end{array}$ & PRR \\
\hline 1955 & $113,430,000$ & $140,000,000$ & --- \\
1980 & $203,242,000$ & $296,015,000$ & 1.74 \\
2005 & $297,613,000$ & $313,777,000$ & 0.19 \\
\hline
\end{tabular}

\section{Data and Analysis}

\section{Disaggregating a Single Age-Group Pair}

An integral part of this study was an examination of the Arrington-style of assembly and the data within it. This included examining the combinations of fields used to calculate annual growth factors (AGF) across large datasets and looking for common elements. AGFs are the fractional change in known recovery size from the same group of fields between one year and the next. To demonstrate this technique, the NRG Associates (2008) database was used to assemble the data in a similar fashion to Verma's (2005) example; table 2 is a reproduction of Verma's table for use as a reference for this form of assembly. These types of sum and percentage calculations are common to the Arrington-style of data assembly and are explained in detail by Attanasi and Root (1994) and Verma (2005). Continuous accumulations as assessed by the USGS were excluded from this dataset to the extent it was possible to accurately identify them. Determination of an oil field versus a gas field was done on the basis of gas to oil ratios (GOR); that is, a field having a cumulative GOR of less than 20,000 standard cubic feet of gas per barrel of oil was designated an oil field, whereas a field with a GOR greater than 20,000 standard cubic feet of gas per barrel of oil was considered a gas field.

Two measures of aggregate reserve growth will be used when discussing the reserve growth of a group of fields: (1) gross reserve growth is the sum of only increasing growth for a group of fields and (2) net reserve growth is the sum of all growth, increasing or decreasing. This distinction is necessary because it is possible to have large volumetric reserve growth yet have zero, or less, net reserve growth. Gross reserve growth is therefore the most useful to calculate the percentage contribution of the total growth from individual fields without shrinking fields masking or exaggerating these types of comparisons.

For the purposes of illustration, we are going to start by examining all the data used to calculate the AGF for a single age-group pair of the Arrington-style assembly. As an example, table 2 contains (1) a single age-group pair contained in the sums of the diagonally highlighted and dashed boxes or (2) nineteen age-group pairs if you consider the difference between each highlighted and dashed box individually. In either case, the percentage difference is calculated between the pairs (be it one or 19) and then an algorithm is used to fit the results. This process is repeated for the next age-group pair(s) with a slightly different combination of fields and continues until there is insufficient data to continue.

For an initial examination, we are going to keep all field information disaggregated and examine all fields within one of these age-group pairs at a known distance in time from the date of discovery, or start of production, and calculate some basic information on that pair. The age-group pair selected is for conventional oil fields in the United States, utilizes the normalized timeframe of 60 and 61 years since discovery, and uses the data at the field level from the NRG Associates (2008) database. The discovery years in this group range from 1922 to 1945 and consist of 1,739 oil fields. Figure 3 is a histogram of the estimated known recovery sizes at year 61 . The total known recovery volume contained in the 61-year age-group pair is $73,074,732,000$ barrels and the total known recovery volume in the year 61 age group total is $73,254,973,000$ barrels. The AGF for this change is 1.0025 . Of the 1,739 fields in the group, 884 increased their estimated ultimate size by $351,803,000$ barrels, 353 decreased by 171,562,000 barrels and 502 had no change; the net volumetric change was $180,241,000$ barrels. The top ten growing fields contained 33.3 percent of the gross field growth and 65.1 percent of the net growth for the entire age-group pair. These ten fields contained 6.2 percent of the total estimated known recovery in the fields contained within this age-group-pair example.

This heavy concentration of growth (33.3-percent gross or 65.1-percent net) in a fraction of the number of fields available ( 0.57 percent) shows that the possibility exists for a small number of fields to dominate individual AGFs within the Arrington-style of data assembly. Grace (2006) noted that field-growth results in his study appeared lognormally distributed (without describing any parameters for this lognormal distribution). Attanasi and Root (1994) noted the presence of outliers within the U.S. oil field data using the Oil and Gas Integrated Field File (OGIFF) from the EIA. Further attention on the implications of skewed reserve-growth results is warranted if the final result appears overly dependent on such a small number of fields. The Arrington-style of assembly uses the data from a single field across as many age-group pairs as the data permit. It is therefore possible that a single field in one age-group pair can heavily influence other age-group pairs. This can be described as a stretching effect in the sense that a single field's estimated recoverable changes can be used in a large number of age-group pairs, effectively stretching its reserve growth influence across a wide swath of an Arringtonstyle assembly. This stretching effect has the potential for a single influential field, or small group of influential fields, to have a corresponding influential effect across a large number of AGF calculations. To determine if this type of behavior exists across the entire spectrum of age-group pairs, it is necessary to expand the analysis to all fields in all age-group pairs and examine them in relation to each other. 
Table 2. Known petroleum volumes (KPVs) for conterminous United States, excluding Federal offshore and continuous fields. From Verma (2005.) [KPVs in million barrels. Data source: 1977-1996 Oil and Gas Integrated Field File. AGF, annual growth factor; D. Year, discovery year]

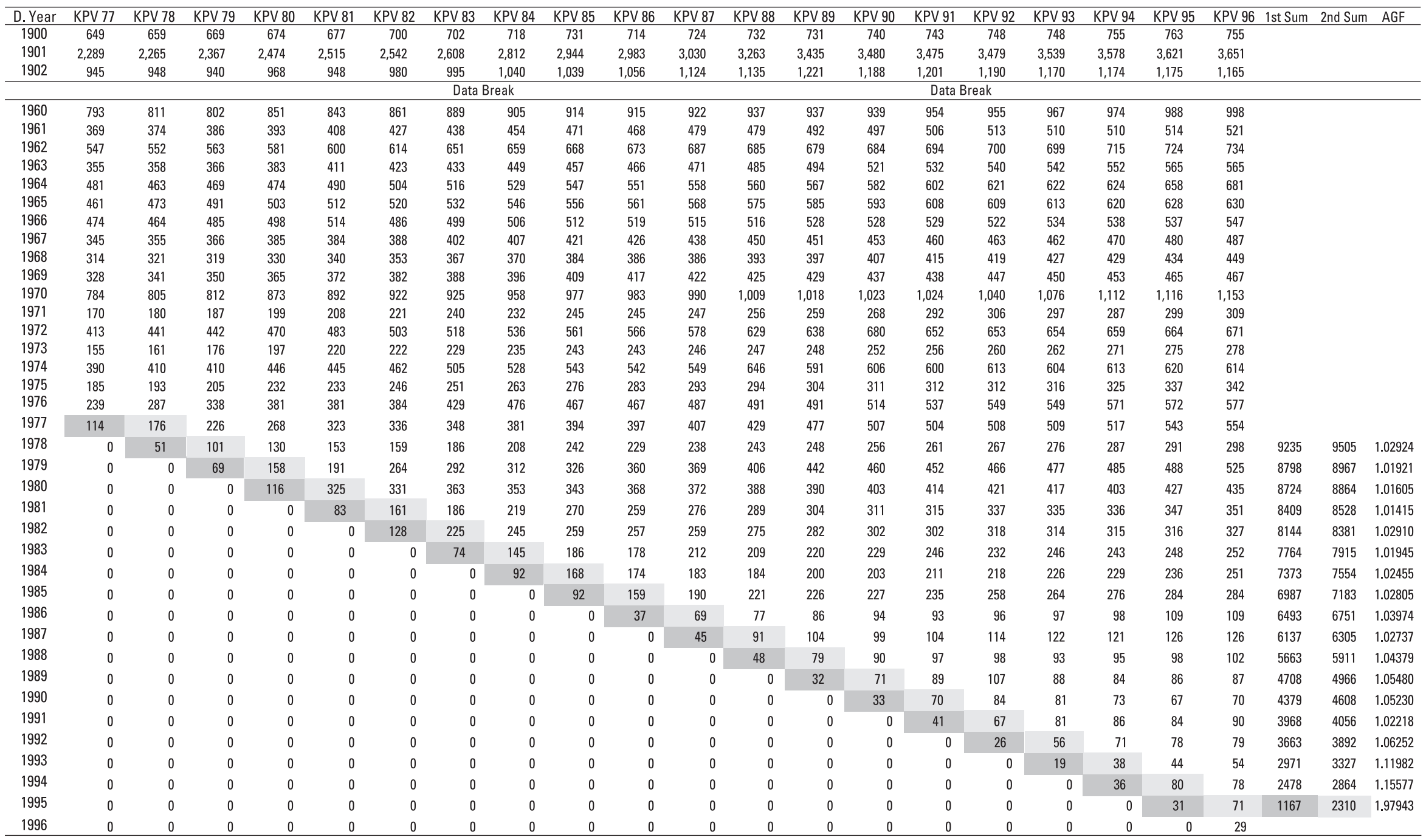




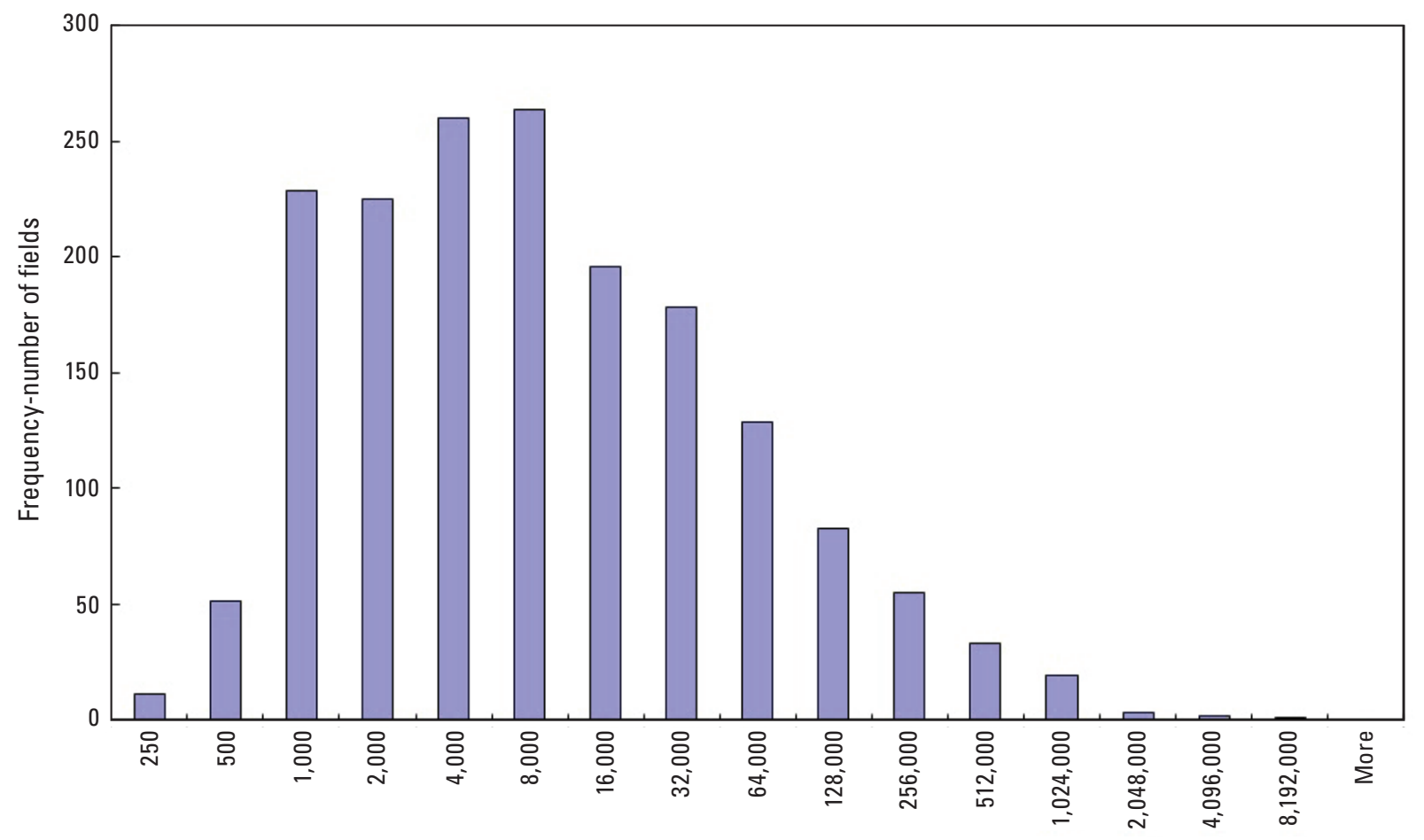

Estimated recoverable oil field sizes (thousand barrels of oil)

Figure 3. Estimated known recoverable oil for conventional oil fields 61 years after discovery year.

\section{Disaggregating All Age-Group Pairs}

Figure 4 is a breakdown of all conventional oil fields meeting the same criteria as listed previously except for all age-group pairs rather than just one. Figure 5 uses the same criteria and shows the average net reserve growth per field per age-group pair since discovery and the dead-field ratio. The dead-field ratio is the percentage of fields in which the cumulative production is equal to or nearly equals the estimated ultimate field size. This was calculated to determine at what point fields become uneconomic and are shut down.

Figures 4 and 5 demonstrate that the average size of older fields is larger than the newer oil fields. The dead-field ratio has an inflection point as data transitions between older and newer oil fields. Average volumetric field growth in the older discovered fields is anomalously large compared to the younger oil fields. These differences justify a further investigation into what appears to be different distributions of results contained within the same dataset.

The discovery of large fields early in the discovery history of a particular area has been documented previously by Arps and Roberts (1958). Of note is that fields in the 85to 105-year age groups show higher growth per field than younger age groups, as much as two orders of magnitude. The dead-field ratio climbs steadily until the maximum field discovery age group is reached, at which point it declines to reflect that these larger and higher growth fields remain in production at higher percentages than smaller fields. After the 105-year age group, the dead-field ratio grows rapidly as the overall average age-group growth drops. The ratio dropping to zero at approximately the 130 -year age group is caused by data scarcity; a single producing field remaining in a dataset comprised of one field signifies a zero-percent dead-field ratio. Also note that the placement of this above-average reserve growth correlates with the age range of the outliers noted by Attanasi and Root (1994), given an additional 15 years of data. These outliers were referenced as being California fields with relatively low API gravities, fitting into the data stream at approximately the 70 - to 80 -year age group. The OGIFF data used by Attanasi and Root (1994) was vintage 1991, and the data used in this study was vintage 2006, placing those outliers in the 85- to 95-year age group.

To determine the approximate number of fields required to reach some arbitrary amount of gross reserve growth in each age-group pair, all fields were arranged from highest to lowest reserve growth. These fields, from largest to smallest, were then counted and their reserve growth summed until 75 percent of the total growth in each age-group pair was accounted for. The estimated ultimate recoverable size of these fields was also summed, and this information is displayed in figure 6. Two things affect the percent of gross growth line in figure 6: data density and a shrinking absolute number of fields with large effects on age-group pairs past year 85 . Except for early and late age-group pairs, less than 10 percent of the fields (and commonly less than 5 percent) in any given age-group pair are required to achieve 75 percent of the gross 


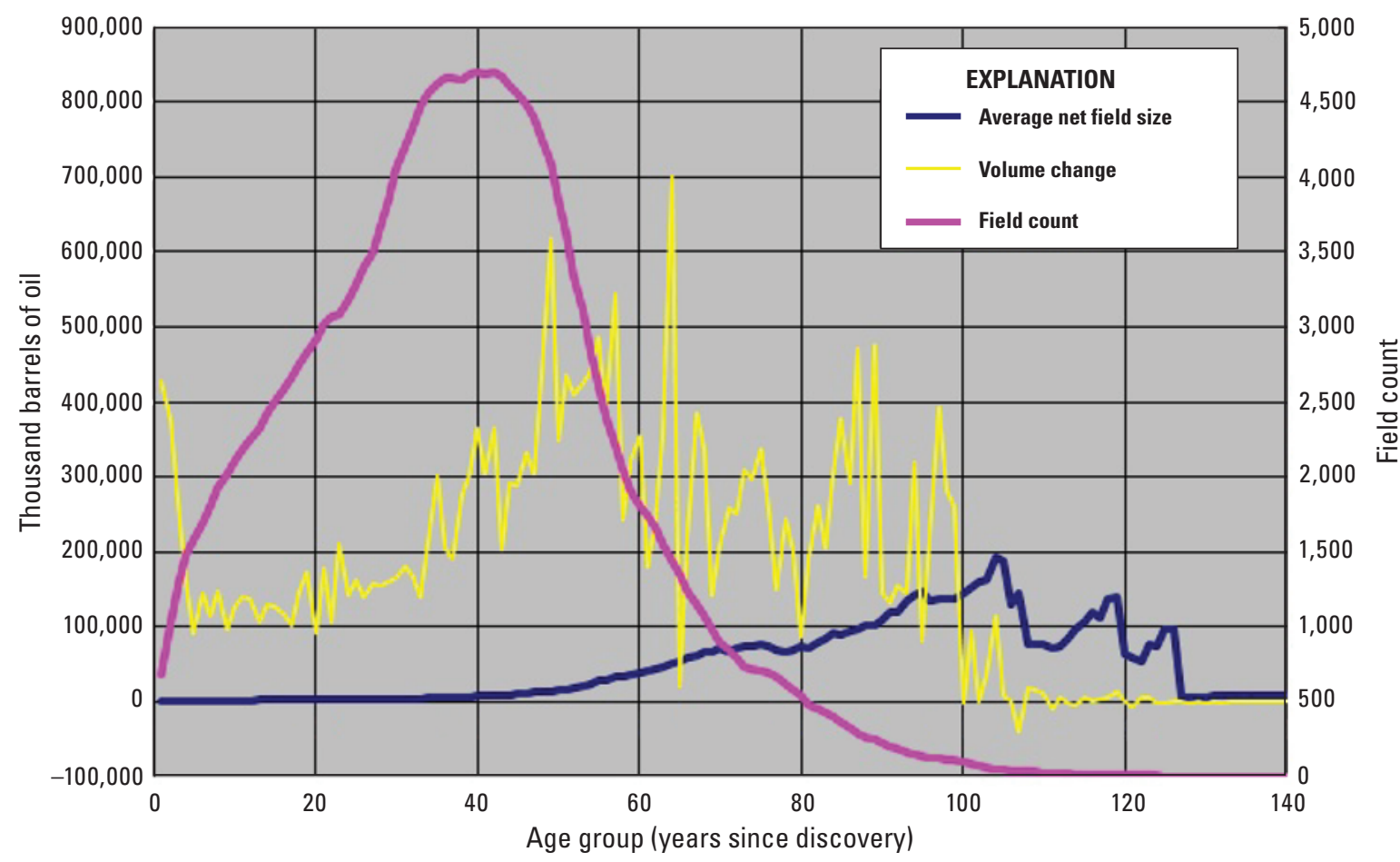

Figure 4. Average conventional oil field size, volume changes, and field counts for all age groups.

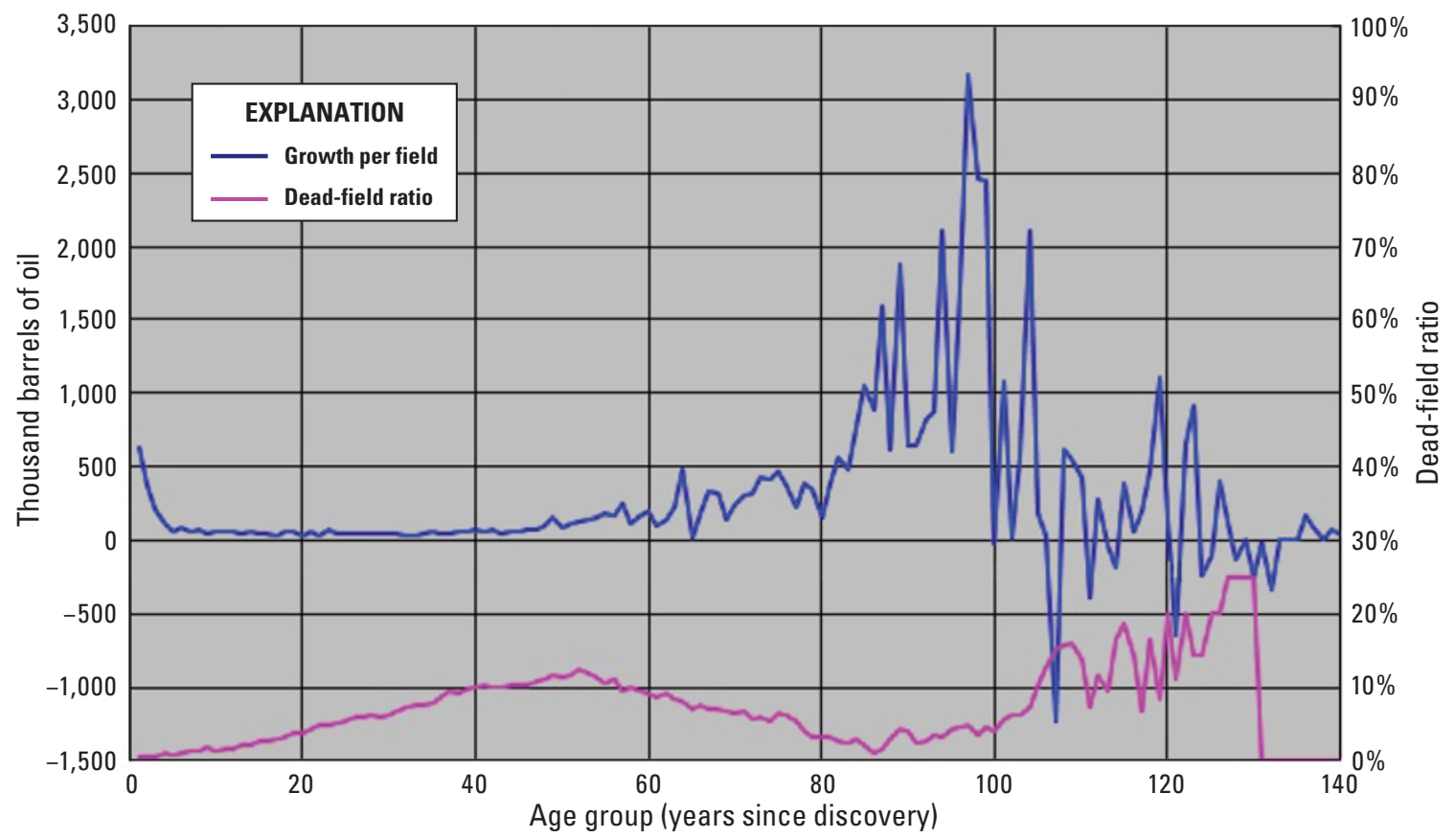

Figure 5. Average reserve growth in conventional oil fields per field per age-group pair including percentage of fields where cumulative production equals estimated known recovery.

reserve growth. The size of their aggregate estimated known recovery within the age-group pair is approximately 25 percent. Stated another way, less than 10 percent of the fields in every age-group pair, encompassing 25 percent of the known recoverable size of the age-group pair, are responsible for 75 percent of the gross volumetric reserve growth.

Based on the contribution of this limited number of fields generating a majority of the reserve growth in each age-group pair, a definition for "major" reserve-growth field was constructed. A "major" field is one generating 2 percent or more of the gross reserve growth in any age-group pair. If the gross reserve growth of the major fields was subtracted out of the total gross growth, it would reveal what contribution toward net reserve growth the remainder of the nonmajor fields would generate. 


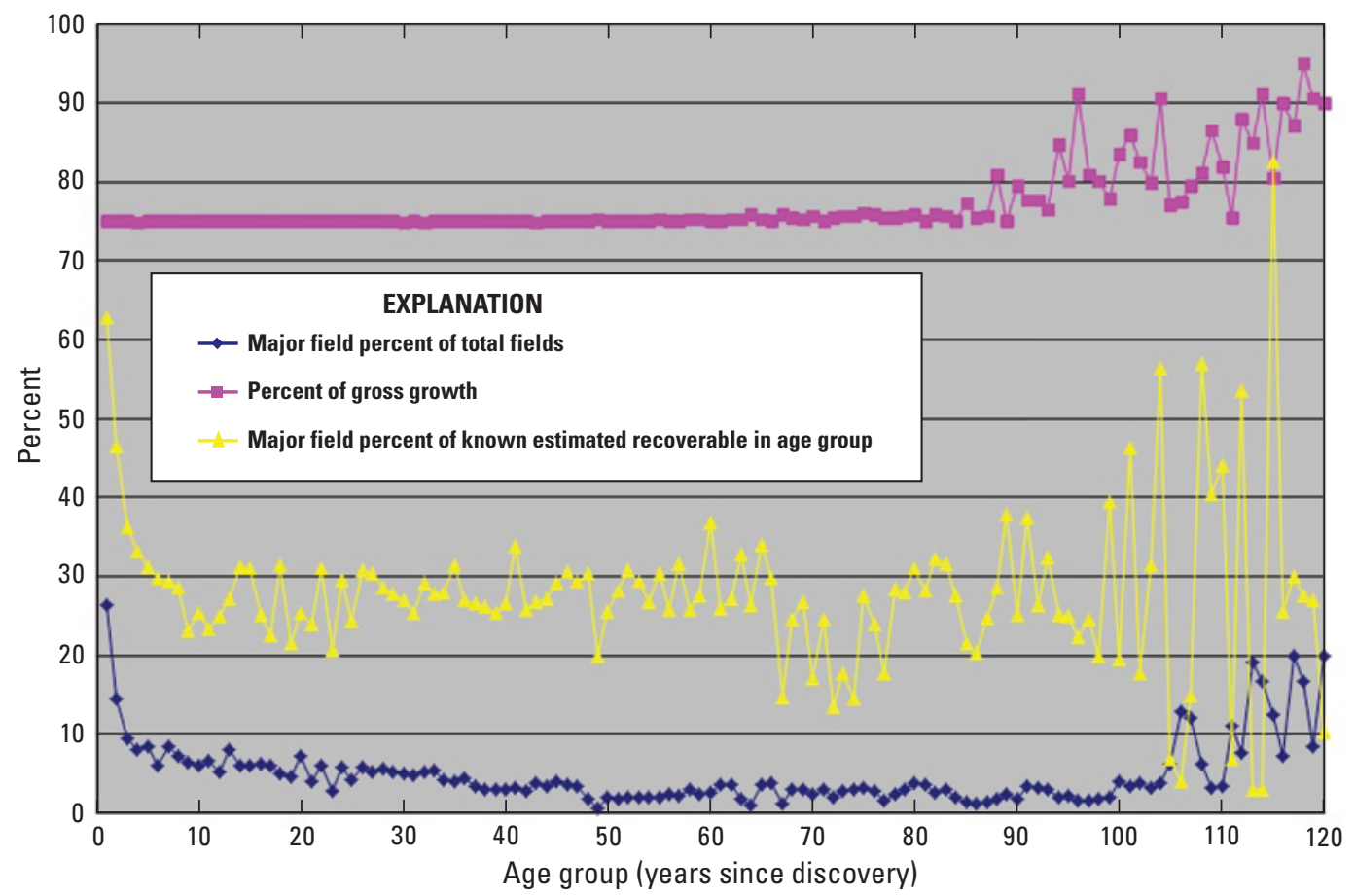

Figure 6. Number and size of oil fields required to generate 75 percent of gross field growth in each age-group pair.

Figure 7 shows that if the major fields are removed from the data, the contribution of the remaining fields falls to nearly zero, and in many cases the result is a decrease in overall net growth. Reserve growth effectively disappears for all but a minority of fields shortly after discovery. By comparing figure 7 to figure 6 , it becomes obvious that (1) the reserve growth built into an Arrington-style assembly is created by less than 10 percent of the fields in most cases, and (2) with the removal of this 10 percent, there is little or no growth left in the remainder.

To better determine how only a few fields might have a substantial impact on gross reserve growth in each age-group pair, the largest growing field for each age-group pair was used to generate figure 8 . As the data density thins toward age-group pair 100, it is reasonable to expect that a single, old producing field might dominate the age-group pair. As demonstrated in figure 8 , nearly 20 percent of the gross reserve growth is dependent on a single oil field after age-group pair 65 and tends to grow through the end of the period for which data are available. Until age-group pair 85 , the percentage of the estimated recoverable sum upon which this growth is based is less than 5 percent.

Figure 9 is constructed in a manner similar to figure 8 , except that the top five growing oil fields are ordered sequentially. By age-group pair 100, nearly all the gross growth can be attributed to the top five fields. By age-group pair 50, these top five fields are accounting for a consistent 35 percent of gross reserve growth. Figure 4 shows that age-group pair 50 has approximately 3,500 fields contained within it. This calculates to approximately 0.14 percent of the fields generating 35 percent or more of the gross volumetric growth in the later years of this particular Arrington-style assembly.

Figure 10 was constructed to examine the dependency of total reserve growth on all major reserve growth fields across all age-group pairs. The number of oil fields meeting this criterion rarely exceeds ten; yet starting at age-group pair 50 , the volumetric contribution of this group grows quickly. The effect of data density on the higher age groups is also more obvious as the major field count drops to a few, at which point nearly all reserve growth is based in that age-group pair. Figure 11 is the same chart assembled from all fields that did not qualify as major contributors and shows the net remaining growth. By age-group 65, the reserve growth of all remaining fields is diminishing, and by age-group 95, there are still 120 fields that are consistently acting as a counterbalance on the growing reserve growth in the 3 or 4 major-contributor fields. For a majority of the 100-year oil fields, reserve growth has ceased.

It is apparent that a relatively small number or small percentage of oil fields are capable of providing reserve-growth volumes out of proportion to what their size or numbers might indicate. Attanasi and Root (1994) mentioned California heavy-oil fields as providing a late-growth spurt to reserve growth, and Tennyson (2005) specifically dealt with some of these California oil fields in the San Joaquin Basin. It would be reasonable to speculate that if these fields were outliers, their imprint would be revealed in the appropriate age-group pairs. 


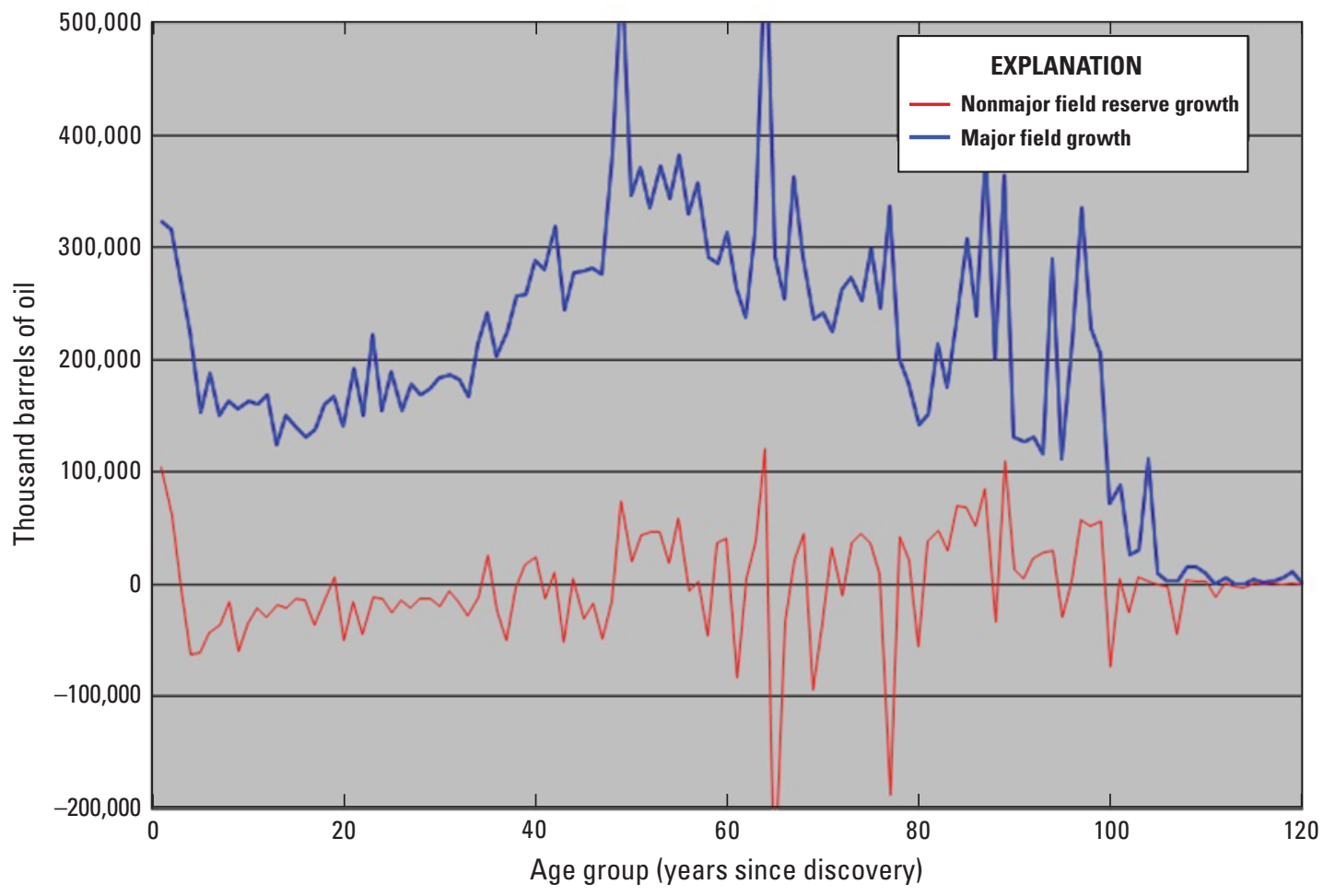

Figure 7. Volumetric contribution of gross reserve growth for major and nonmajor conventional oil fields in each age group. Major fields are those that contribute more than two percent of the gross reserve growth in an age-group pair.

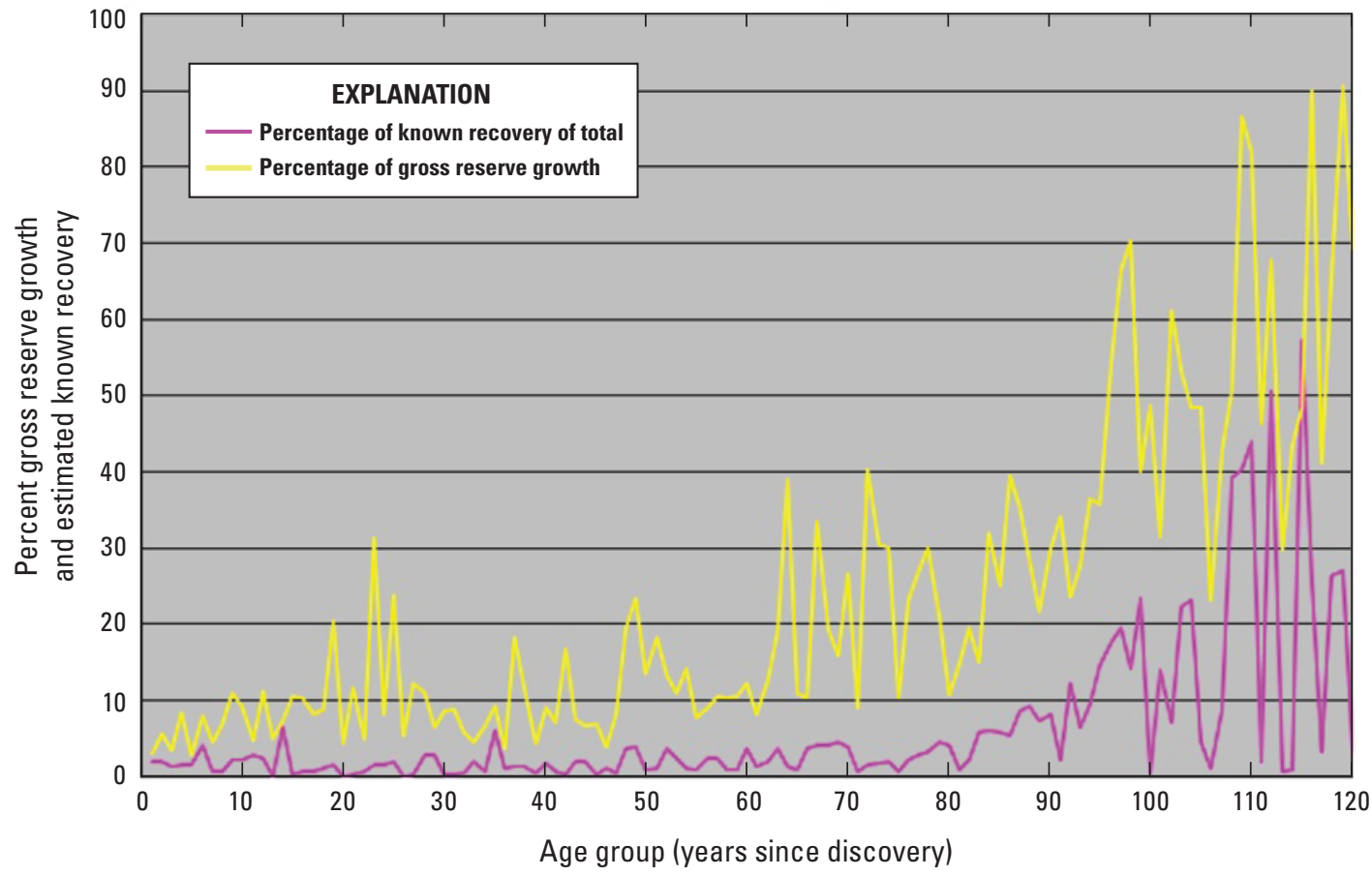

Figure 8. Percentage of gross reserve growth and total known recovery of the single largest growing oil field in each age-group pair. 


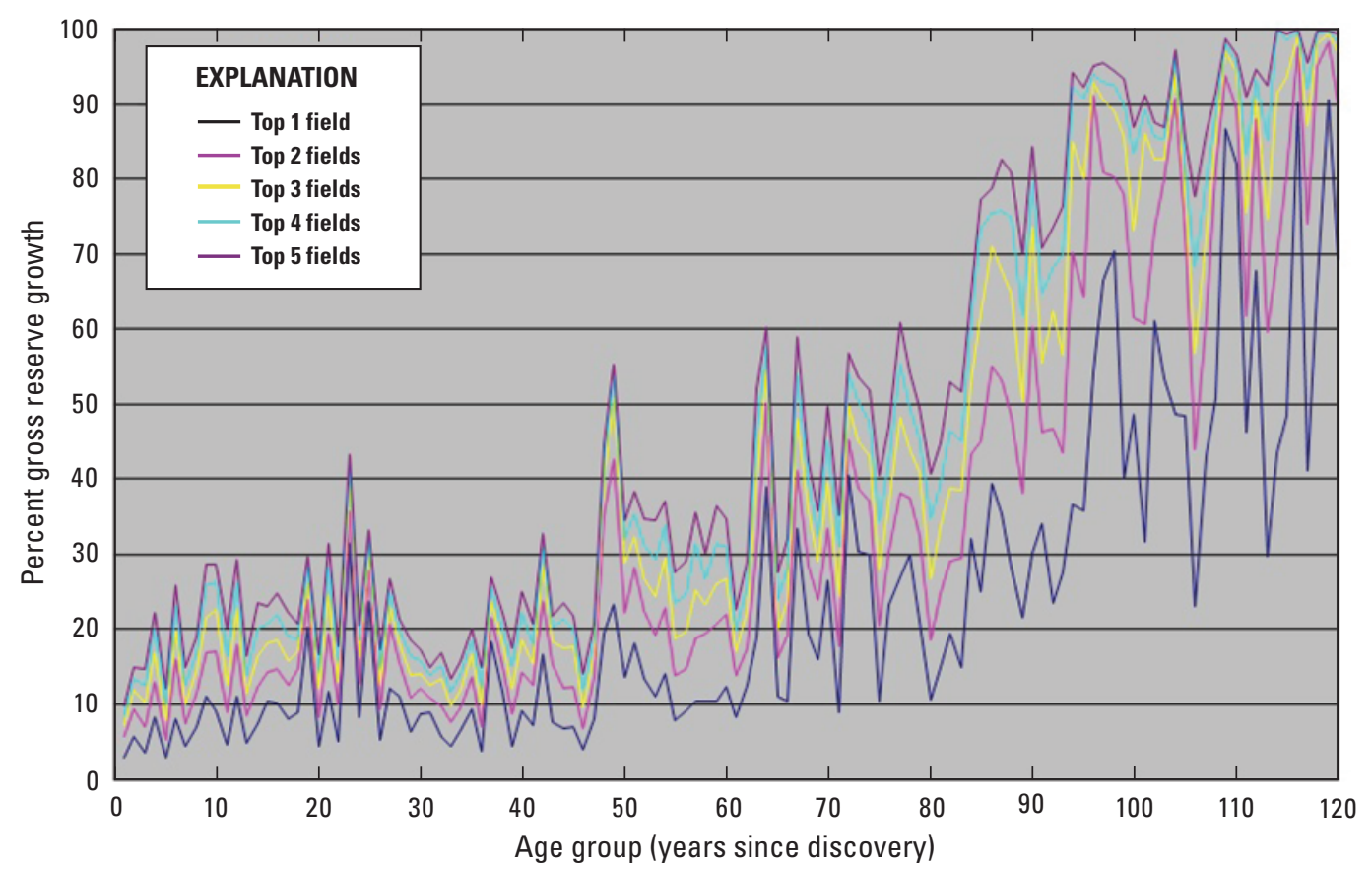

Figure 9. Gross reserve growth of five largest growing oil fields in each age group.

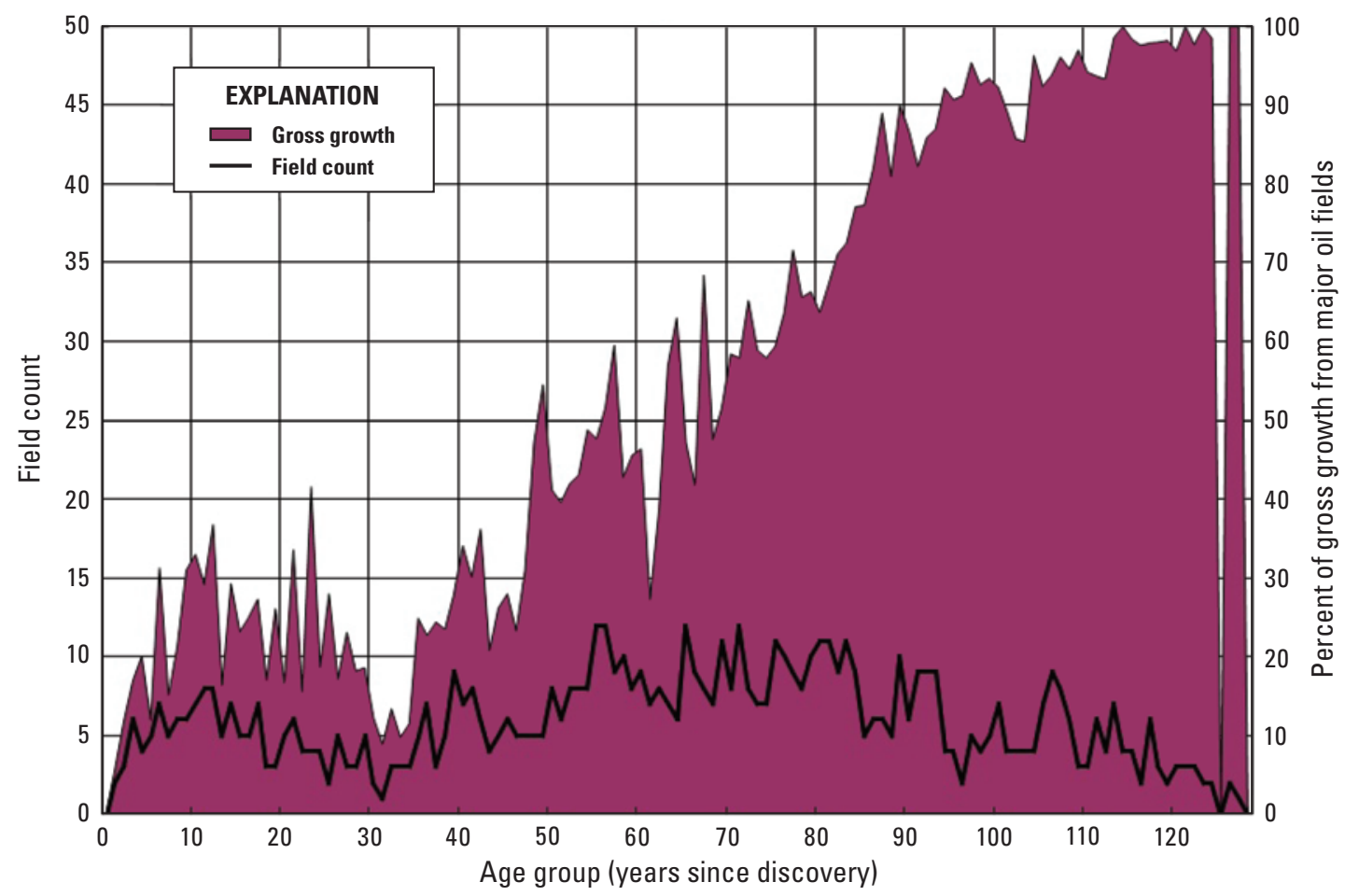

Figure 10. Field counts and gross reserve growth of major oil fields. A major field is any field that contains more than two percent of the gross growth in a single age group. 


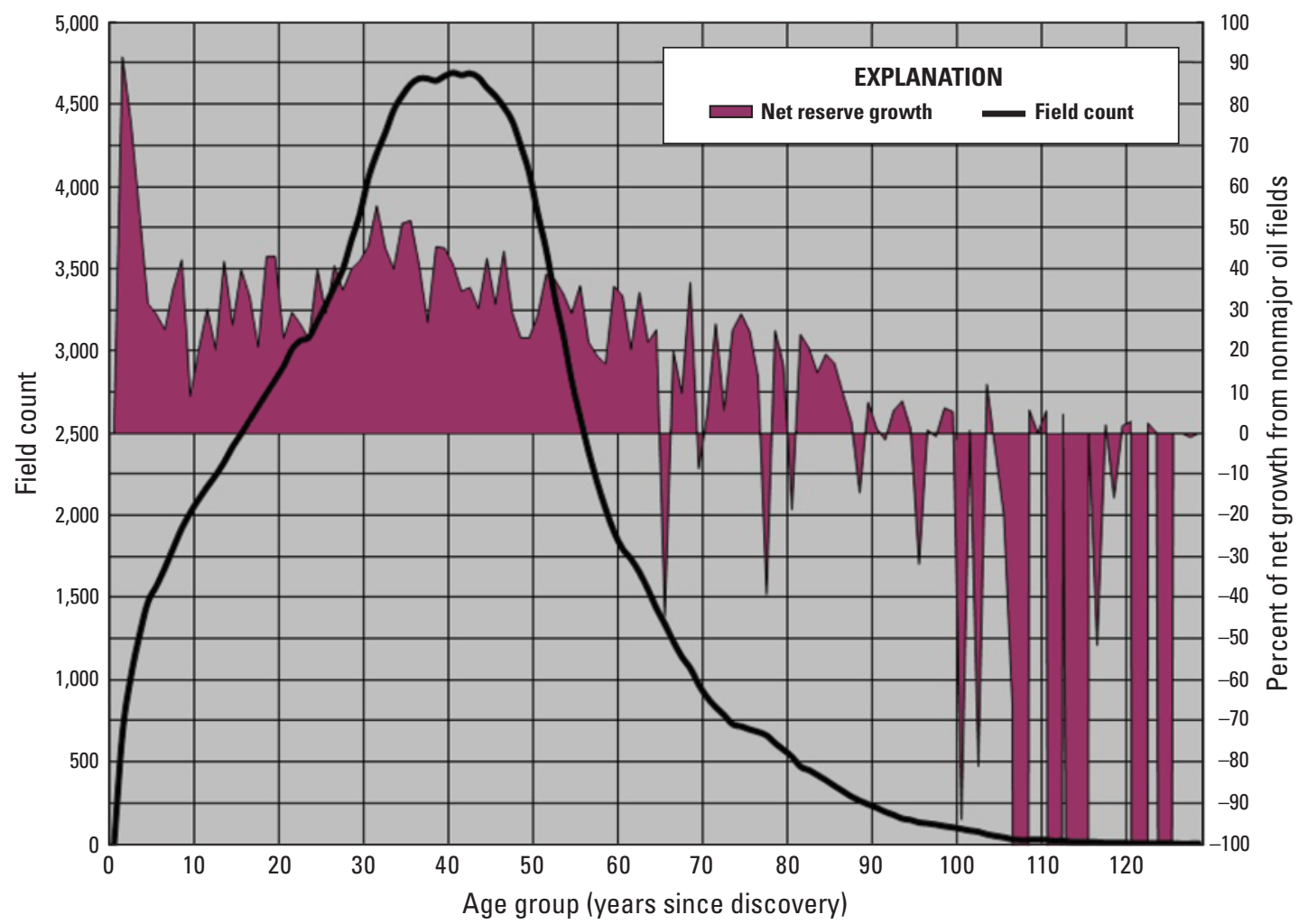

Figure 11. Field counts and net reserve growth of nonmajor oil fields. Nonmajor oil fields are all of those not included in figure 10 .

Figure 12 shows the amount of net reserve growth of each age-group pair for all fields in the San Joaquin Basin. Starting at about the 70-year age group, the effect of the San Joaquin oil fields begins at 20 to 40 percent of the net growth, and by year 85 it increases to 80 percent or more through age-group pair 110. Net reserve growth larger than 100 percent indicates that the sum of the growth of all other fields is negative (shrinkage) and is counterbalancing the growth shown. At approximately the same point where the San Joaquin reserve growth begins to increase, the volumeweighted API gravity of all reserve growth in the United States begins to decrease reflecting the nature of the heavier API-gravity oils in this basin.

The examples presented in foregoing discussions have all focused on conventional oil fields. The possibility exists that conventional gas fields have a completely different profile of growth or shrinkage, or have different dependencies on differing numbers of fields. Figures 13 and 14 are similar to figures 10 and 11 in that they are both based on the concept of major contributors to reserve growth (fields producing greater than two percent of the gross growth within any given age-group pair), except that figures 13 and 14 are based on all conventional natural gas fields in the NRG Associates (2008) database. Reserve growth in natural gas fields becomes dependent on fewer fields within each age-group pair in less time than oil fields. Also net reserve growth for the nonmajor contributors reaches zero and becomes negative more consistently and quickly, so that by age-group 70, reserve growth on all but the major contributors has effectively ceased. At that time, the major contributors are supplying at least 75 percent of the gross growth and are increasing rapidly afterwards.

So far this analysis has concentrated on quantifying the effect that a limited number of fields has within each agegroup pair. However, any one field within an Arrington-style assembly has the potential to affect each age-group pair that it resides within. Potentially a single field could have enough reserve growth within an age-group pair to make any function derived from the Arrington-style of assembly completely dependent on that field. Figure 15 is a plot of 13 fields, ranging through age-group pairs 48 to 126 , and their individual and combined contributions to the gross reserve growth in each pair. The overall field count in each age group is also included because there are less data for the older age groups.

This disaggregation of the age-group pairs reveals that gross reserve growth in many age-group pairs is dependent on a small number of fields, regardless of the exact field combinations composing any particular age-group pair. The older the field discovery date the more the age-group pairs become dependent on relatively smaller numbers of fields for the gross reserve growth in any age-group pair because other fields cease growing. Further, the Arrington-style of assembly allows this effect to continue across other age-group pairs, so any 


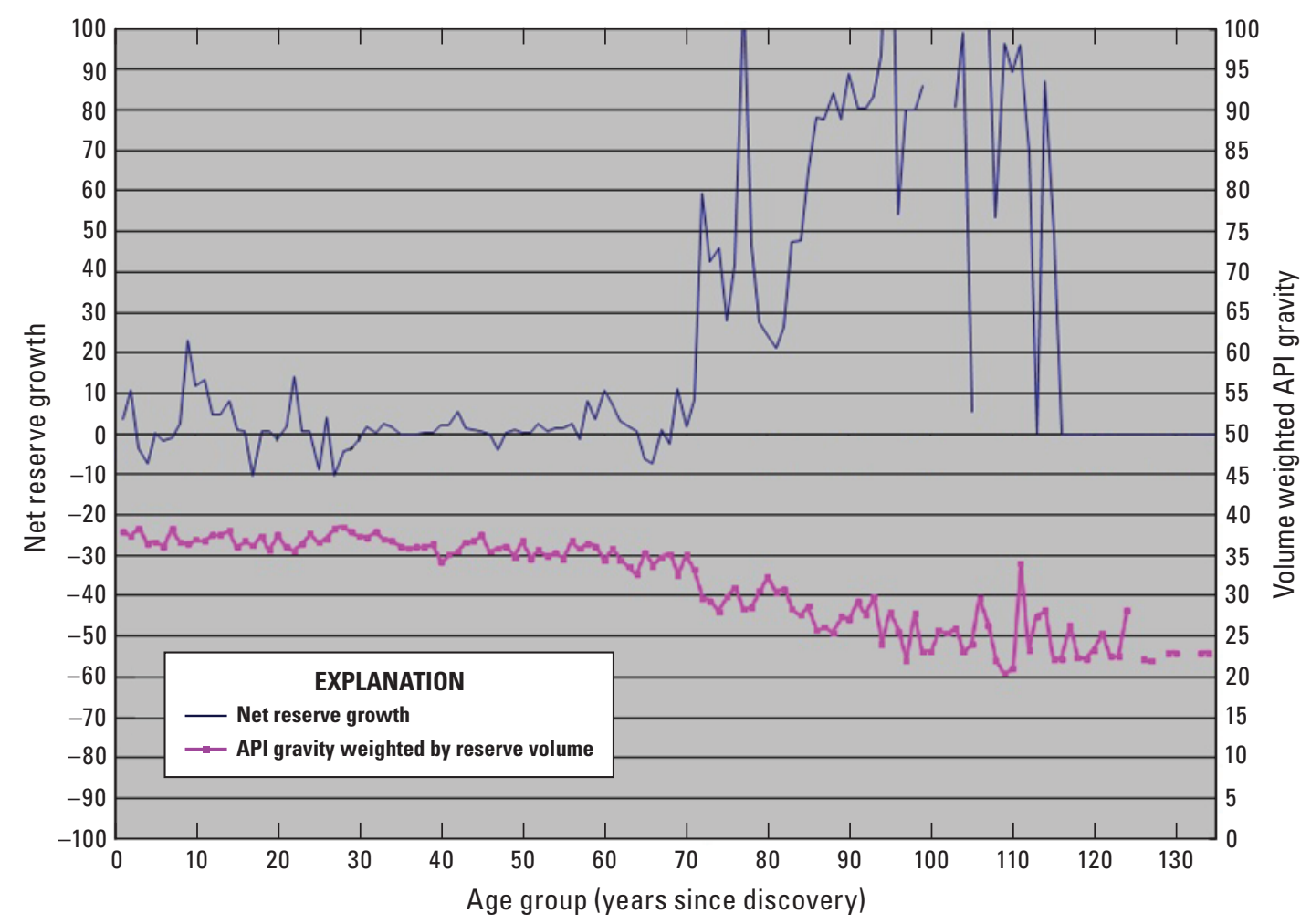

Figure 12. Net reserve growth from San Joaquin Basin oil fields and volumetrically weighted reserve growth by American Petroleum Institute (API) oil gravity. Net reserve growth above 100 percent indicates offsetting reserve shrinks in the same age-group pair.

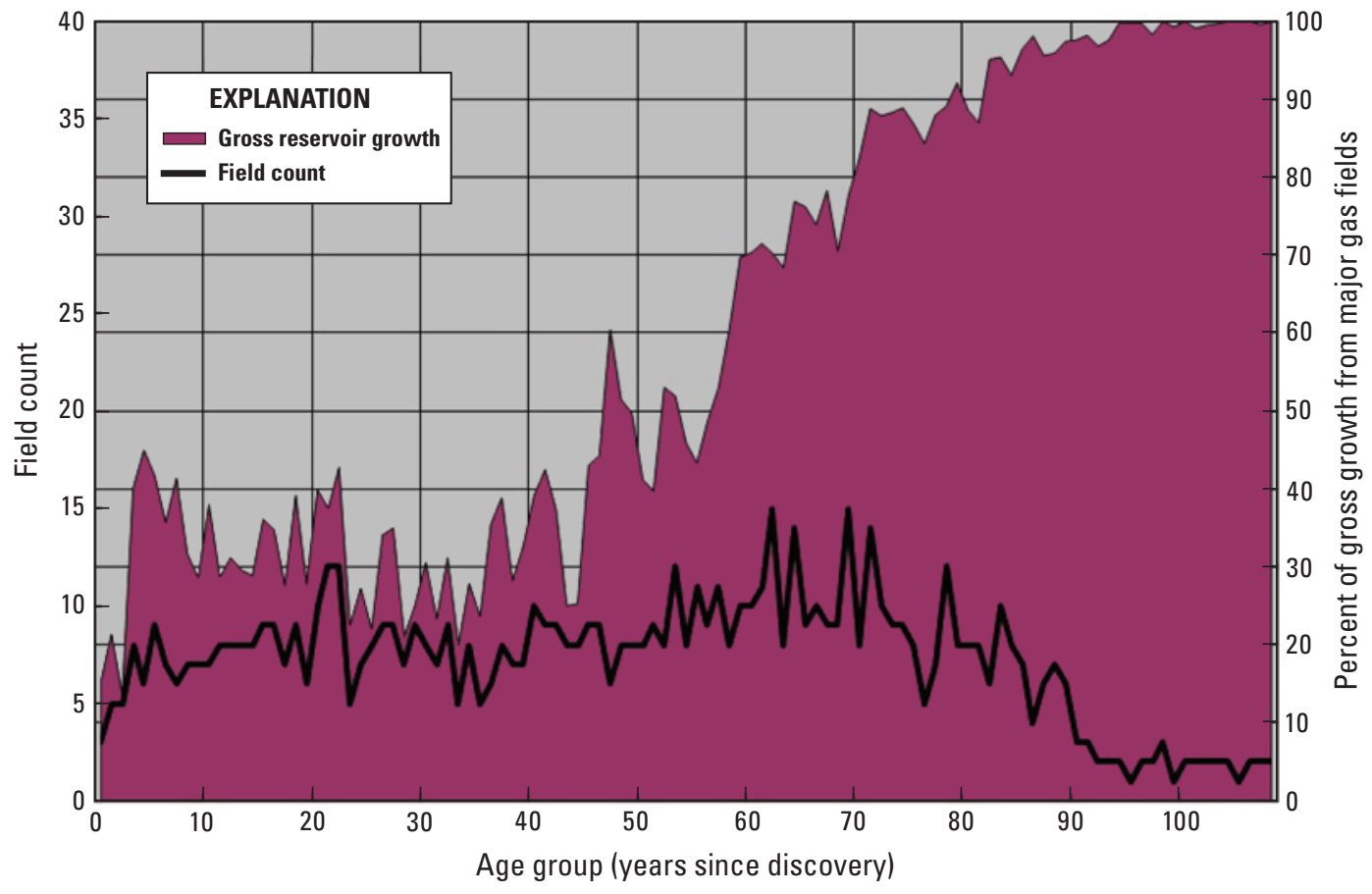

Figure 13. Field counts and gross reserve growth of major gas fields. A major gas field is any field that contains more than two percent of the gross growth in a single age group. 


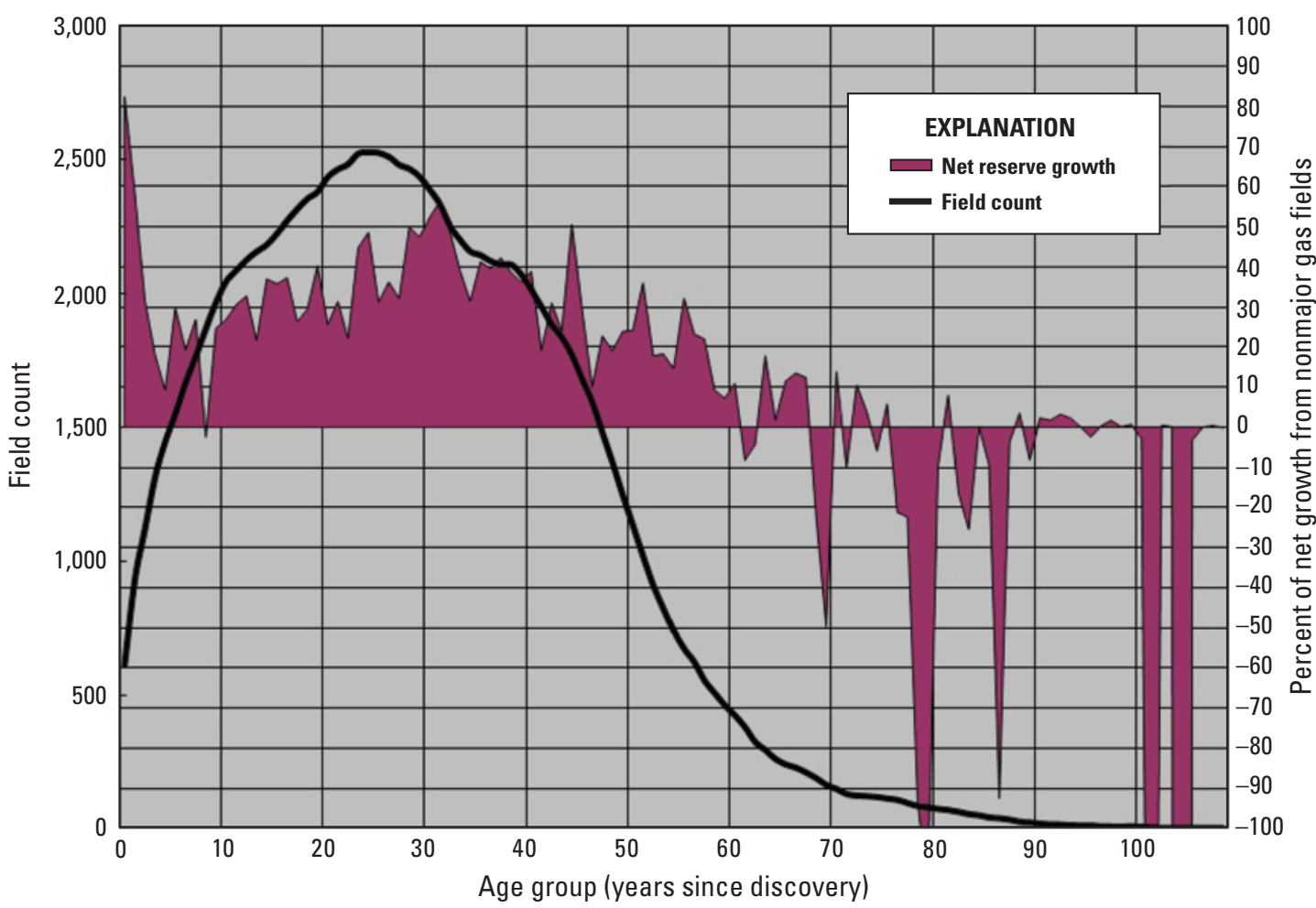

Figure 14. Field counts and net reserve growth of nonmajor gas fields. Nonmajor gas fields are all of those not included in figure 13.

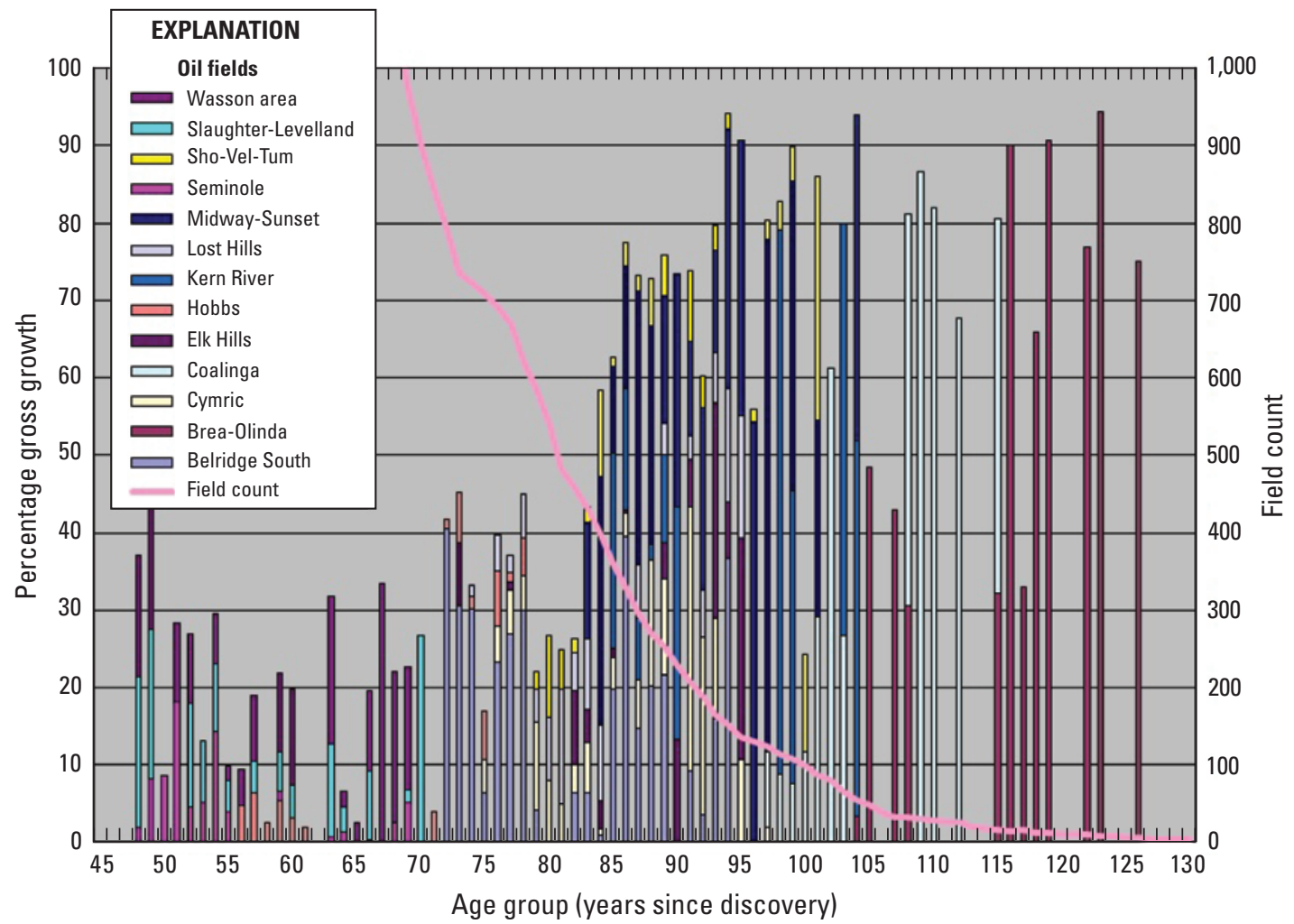

Figure 15. Gross reserve growth of oil from a few fields across multiple age-group pairs. 
one field can actually dominate as many age-group pairs as are represented in the data for that field. In this study, the data strings are for 24 years, so that number minus one would be the maximum number of age-group pairs (23) any single field could affect.

\section{Natural Tendencies of the Arrington-Style Assembly}

The Arrington-style assembly for reserve growth is a specific combination of (1) volumetric weighting, (2) conversion to a percentage change for a particular group, and (3) some type of best fit to the resulting percentage changes across the entire timespan. This construction uses data of different time periods from a discovery date to assemble a long string of AGFs from shorter data strings. Arrington's method can be used to construct these AGFs for a single long string of data providing the same sort of "running rate of growth" configuration without best-fitting multiple data pairs at every age step in the calculation.

Table 3 consists of the discovery-year age groups for the first 23 years of an actual age-group sequence of oil fields from the NRG Associates (2008) database. Starting with year 24 , the values listed are extrapolations based on a 2-percent exponential decline in the changes in known recovery. This extrapolation is illustrative of some hypothetical measure of future growth for this group of fields used in this example. The data from the NRG Associates (2008) database are used for calculations of the AGFs (column 5) and cumulative growth functions (CGFs) (column 6). Column 7 is based on the assumption that a field beginning from the year of discovery has a stable-inventory profile that accounts for 0.6 percent of the first-year growth in known recoverable volumes. The difference between this field and all the others in the group is that it will consistently grow this amount year by year in the manner of a stable-inventory profile. Table 3 shows the increasing relative value of this type of growth profile extrapolated over 100 years. A single field maintaining steady growth can increase from 0.6 percent of the growth in a given age group to more than 40 percent in 100 years.

Though this simulated stable inventory field has a small initial starting point and minor but consistent growth year after year, it should be noted that this type of profile (1) establishes an ever-increasing denominator in an Arrington-style assembly and (2) creates a natural decay function such that even a small amount of static growth can dominate a given group in a reasonable amount of time. This effect can best be explained by the following statement: The sum of change in multiple, nonlinearly declining datasets can become dominated by an individual string given enough time and a slightly lower decline rate between it and the others. Thought of another way, this is an example of negative compounding interest. Figure 16 is a graphical representation of this basic idea. Given nine exponential declines of varying rates (in black) and one with a smaller decline (in red), the one with the smaller decline can dominate the changes of the entire group given adequate time. The speed required for this domination to present itself depends on the smallest decline's relative starting position and the difference in decline rate between itself and the next closest decline. If all declines are similar, as they might be with a small group of fields all operated in the same manner by the same operator, this effect may never manifest itself. Given sufficient time, the dependency of the sum of the change on the single anomaly will be complete. Figure 17 shows the rate at which the smallest decline in the example dominates the sum of the changes in the group. In the case presented, the decline rate difference between the smallest decline and the rest of the group is two-thirds less than the mean of the others. Even much smaller differences in decline rate between the smallest decline and the main group can make a difference.

The best way to display the rapidity with which the dependency develops is to create a simple sensitivity analysis. An example, illustrated in figure 16, is for a group of declines varying from 10 to 20 percent per unit of time and with starting points ranging from 1,500- to 2,500-rate units at time zero. A rate unit in this case represents a rate in any consistent units. An additional hypothetical decline will vary from the mean decline of all others downward to one-eighth of its original value, and its initial starting point will be at least two-thirds lower than all others. Five simulations for decline rates of $15.0,10.0,7.5,5.0$, and 2.5 percent were run at six different time points starting at time zero and continuing through 100 time units. When the additional hypothetical decline is the same size as the mean of all other declines, there is no anomalous dependency on this hypothetical decline. As the difference between the hypothetical decline and the mean decline of the rest of the group widens, however, the hypothetical decline begins to dominate any sum of changes calculation. In the most extreme case, the hypothetical decline already represents a majority of the change somewhere between 25 and 50 time units. However, even a decline rate that is half of the mean of the rest of the group is enough for the single hypothetical decline to dominate the behavior of the group.

The simulation results in figure 18 show how quickly an anomalous decline dominates a group based on differences in time and decline rates. The answers for each scenario are expressed as an envelope of probability to describe the uncertainty associated with how this particular Monte Carlo simulation was designed. Use of this type of presentation readily demonstrates that the size and effect of an anomalous decline is nonlinear in nature and has reasonable, but not extreme, uncertainty associated with each particular scenario. A summary statement for figure 18 might best be described as "He who declines the least wins."

There is a related side effect to this issue as well. The sum of change in multiple nonlinear declines will tend to be hyperbolic until the smallest decline is responsible for all of the volumetric growth. As each decline asymptotically approaches zero, the absolute value of the change it provides to the total also approaches zero. Various individual declines 
Table 3. Single age-group sequence of known recovery change and related calculations.

Bold numbers are real data from NRG and Associates (2008) database; italic numbers are hypothetical extrapolations; MBBL, thousand barrels.

\begin{tabular}{|c|c|c|c|c|c|c|c|}
\hline (1) & (2) & (3) & (4) & (5) & (6) & (7) & (8) \\
\hline $\begin{array}{c}\text { Age } \\
\text { group }\end{array}$ & $\begin{array}{c}\text { Known recoverable } \\
\text { year start }\end{array}$ & $\begin{array}{c}\text { Known recoverable } \\
\text { year end }\end{array}$ & $\begin{array}{c}\text { Change in known } \\
\text { recoverable }\end{array}$ & $\begin{array}{c}\text { AGF } \\
\text { annual } \\
\text { growth factor }\end{array}$ & $\begin{array}{c}\text { CGF } \\
\text { cumulative } \\
\text { growth factor }\end{array}$ & $\begin{array}{l}\text { Known recovery from } \\
\text { stable inventory }\end{array}$ & $\begin{array}{l}\text { Percentage of growth } \\
\text { from stable inventory }\end{array}$ \\
\hline & (MBBL) & (MBBL) & (MBBL) & & & (MBBL) & (Percent) \\
\hline 1 & 23,455 & 67,735 & 44,280 & 2.8879 & 2.8879 & 250 & 0.6 \\
\hline 2 & 69,325 & 95,640 & 26,315 & 1.3796 & 3.9841 & 250 & 1.0 \\
\hline 3 & 96,240 & 121,535 & 25,295 & 1.2628 & 5.0312 & 250 & 1.0 \\
\hline 4 & 142,351 & 150,156 & 7,805 & 1.0548 & 5.3071 & 250 & 3.2 \\
\hline 5 & 150,156 & 152,679 & 2,523 & 1.0168 & 5.3962 & 250 & 9.9 \\
\hline 6 & 152,679 & 157,155 & 4,476 & 1.0293 & 5.5544 & 250 & 5.6 \\
\hline 7 & 157,155 & 163,090 & 5,935 & 1.0378 & 5.7642 & 250 & 4.2 \\
\hline 8 & 163,090 & 175,340 & 12,250 & 1.0751 & 6.1972 & 250 & 2.0 \\
\hline 9 & 175,340 & 186,928 & 11,588 & 1.0661 & 6.6067 & 250 & 2.2 \\
\hline 10 & 186,928 & 180,567 & $-6,361$ & 0.9660 & 6.3819 & 250 & -3.9 \\
\hline 11 & 180,567 & 178,710 & $-1,857$ & 0.9897 & 6.3163 & 250 & -13.5 \\
\hline 12 & 178,710 & 182,468 & 3,758 & 1.0210 & 6.4491 & 250 & 6.7 \\
\hline 13 & 182,468 & 182,690 & 222 & 1.0012 & 6.4569 & 250 & 112.6 \\
\hline 14 & 182,690 & 184,608 & 1,918 & 1.0105 & 6.5247 & 250 & 13.0 \\
\hline 15 & 184,608 & 186,801 & 2,193 & 1.0119 & 6.6022 & 250 & 11.4 \\
\hline 16 & 186,801 & 189,107 & 2,306 & 1.0123 & 6.6838 & 250 & 10.8 \\
\hline 17 & 189,107 & 194,704 & $\mathbf{5 , 5 9 7}$ & 1.0296 & 6.8816 & 250 & 4.5 \\
\hline 18 & 194,704 & 199,043 & 4,339 & 1.0223 & 7.0349 & 250 & 5.8 \\
\hline 19 & 199,043 & 203,487 & 4,444 & 1.0223 & 7.1920 & 250 & 5.6 \\
\hline 20 & 203,487 & 206,665 & 3,178 & 1.0156 & 7.3043 & 250 & 7.9 \\
\hline 21 & 206,665 & 208,829 & 2,164 & 1.0105 & 7.3808 & 250 & 11.6 \\
\hline 22 & 208,829 & 212,574 & 3,745 & 1.0179 & 7.5132 & 250 & 6.7 \\
\hline 23 & 212,574 & 215,403 & 2,829 & 1.0133 & 7.6131 & 250 & 8.8 \\
\hline 30 & 231,228 & 233,684 & 2,456 & 1.0106 & 8.2593 & 250 & 10.2 \\
\hline 35 & 243,026 & 245,246 & 2,220 & 1.0091 & 8.6679 & 250 & 11.3 \\
\hline 40 & 253,690 & 255,697 & 2,007 & 1.0079 & 9.0373 & 250 & 12.5 \\
\hline 45 & 263,330 & 265,144 & 1,814 & 1.0069 & 9.3712 & 250 & 13.8 \\
\hline 50 & 272,044 & 273,684 & 1,640 & 1.0060 & 9.6730 & 250 & 15.2 \\
\hline 55 & 279,921 & 281,403 & 1,482 & 1.0053 & 9.9458 & 250 & 16.9 \\
\hline 60 & 287,041 & 288,380 & 1,340 & 1.0047 & 10.1924 & 250 & 18.7 \\
\hline 65 & 293,476 & 294,687 & 1,211 & 1.0041 & 10.4154 & 250 & 20.6 \\
\hline 70 & 299,294 & 300,388 & 1,095 & 1.0037 & 10.6168 & 250 & 22.8 \\
\hline 75 & 304,552 & 305,542 & 989 & 1.0032 & 10.7990 & 250 & 25.3 \\
\hline 80 & 309,305 & 310,200 & 894 & 1.0029 & 10.9636 & 250 & 28.0 \\
\hline 85 & 313,602 & 314,410 & 808 & 1.0026 & 11.1124 & 250 & 30.9 \\
\hline 90 & 317,486 & 318,216 & 731 & 1.0023 & 11.2470 & 250 & 34.2 \\
\hline 95 & 320,996 & 321,657 & 661 & 1.0021 & 11.3686 & 250 & 37.8 \\
\hline 100 & 324,169 & 324,767 & 597 & 1.0018 & 11.4785 & 250 & 41.9 \\
\hline
\end{tabular}

approaching zero at different rates and times has the group appearance of an ever flattening decline, closely similar to a hyperbolic decline. If the final decline was to change its behavior at this point in time, the group behavior will mimic it.

This example is not meant to be directly representative of reserve growth but to be more of an illustration of how a particular nonlinear decline can come to dominate a particular group if given the time and difference in decline rate. Total growth in known recovery for a group ultimately declines with time, but the question of what that growth is predicated on within a particular type of data assembly is critical to building a more accurate means of estimating future reserve growth.

Figure 19 shows how a large number of these single discovery-year age groups grow from their discovery year to varying time periods based on the length of time of the data available. Growth during the first five years is relatively pronounced, and then there is a profile of slow but steady increases. Also noticeable is a trend toward smaller initial discovered volumes year after year. The fields represented in figure 19 are important because an Arrington-style of assembly would use this group to generate the early growth AGFs upon which all later AGFs would multiply against.

Once it becomes apparent that a small number of fields are actually the drivers of reserve growth within any particular age group, it is reasonable to explore how the removal of those fields would affect an Arrington-style assembly. Figure 20 is a plot showing changes in the AGFs for the top five oil fields in each age-group pair versus all other fields; it demonstrates how rapidly AGFs fall below 1 percent per annum without the inclusion of this particular minority of fields. Similar to what has been shown in figures 13 and 14, once the actual growing fields have been located and removed there is only minor growth in the remaining majority of fields. Figure 21 depicts 


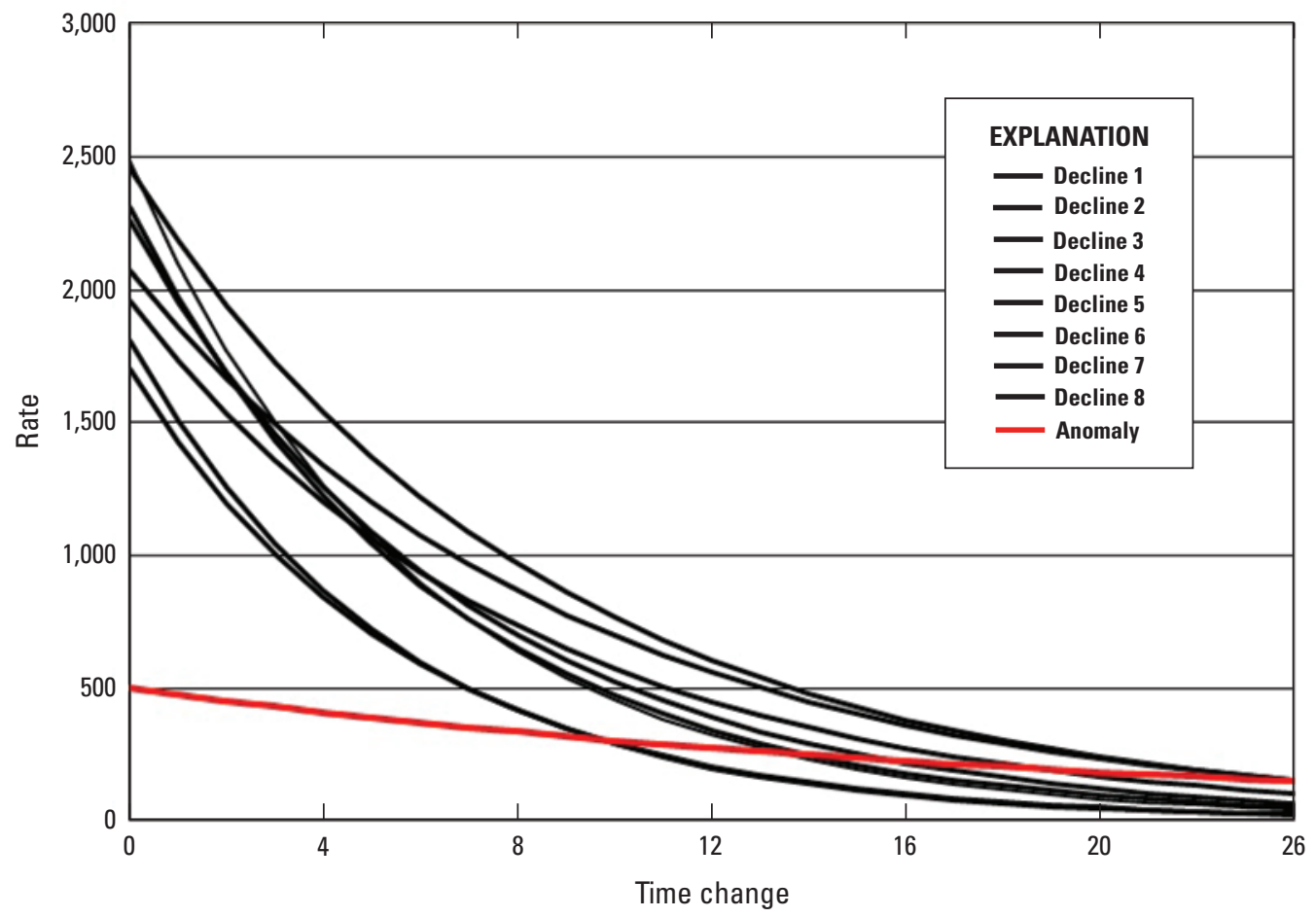

Figure 16. Example of the interaction of nine nonlinear declines.

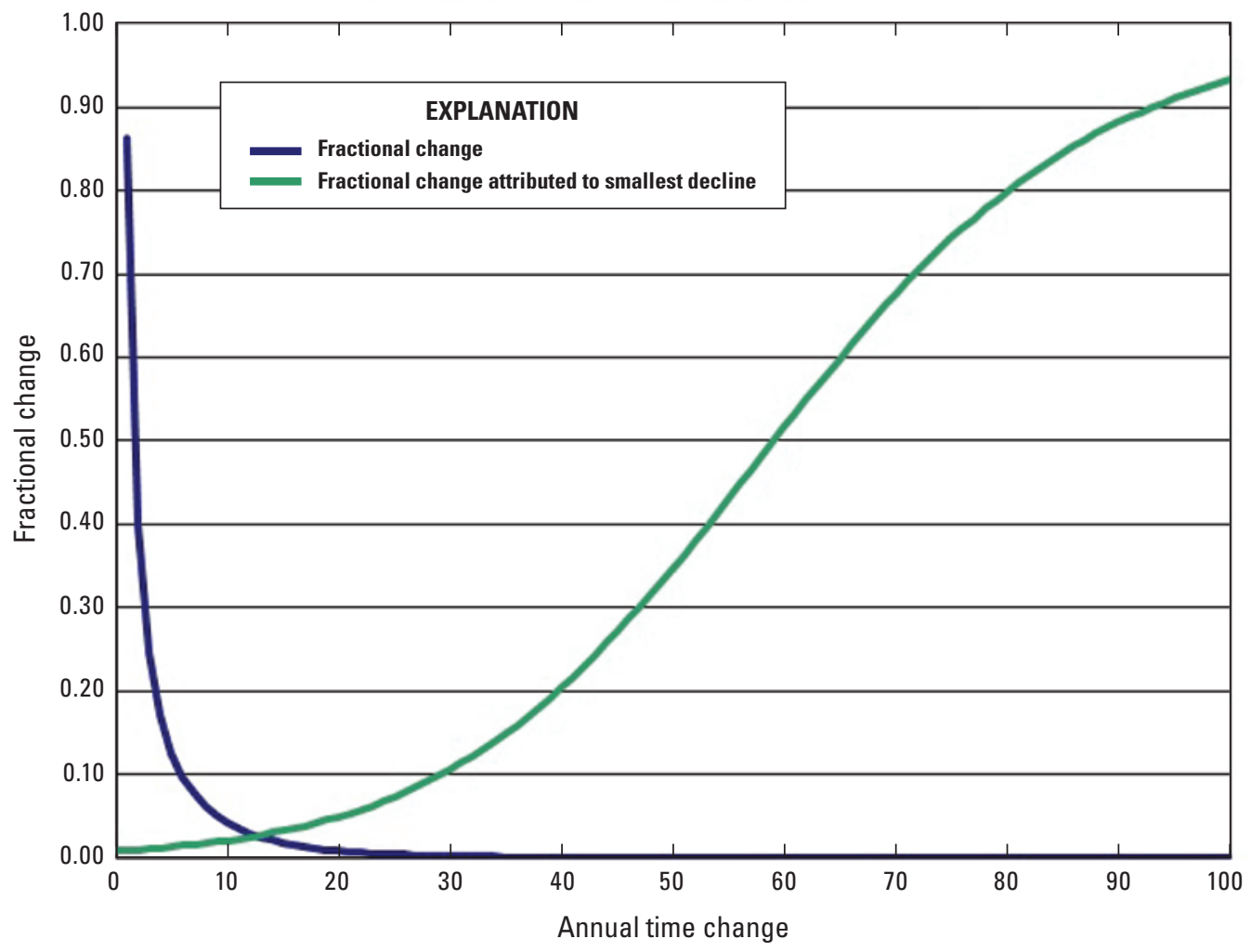

Figure 17. Annual fractional change of nine nonlinear declines and dependency of that answer on smallest decline. 


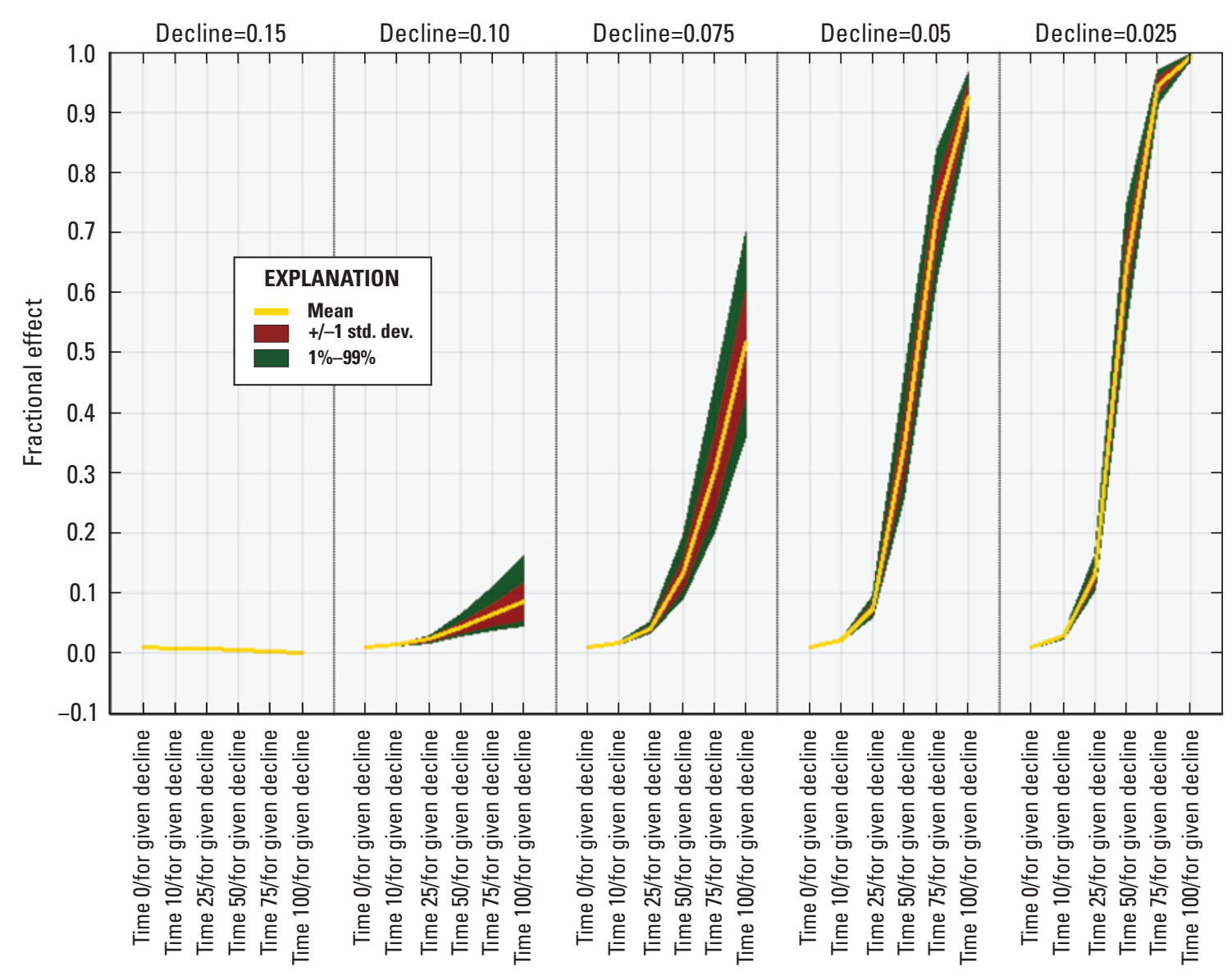

Figure 18. Fractional effect on group behavior caused by the difference between group behavior and the single smallest decline within the group. Std. dev., standard deviation.

a similar relation when the top five gas fields are withdrawn from the overall data and are calculated separately versus all other fields, except that the early precipitous drop-off in initial growth is less pronounced. A cumulative growth curve (created by sequential multiplication of AGFs) constructed from either of these sets of AGFs for oil and gas (figs. 20 and 21) tends to give a final cumulative answer of 4 to 7 for the smaller contributing fields and a multiplier of 10,000 to 100,000 for the top five fields in both cases. It is not assumed that cumulative curves constructed from either of these AGFs are representative or comparative.

\section{Conventional Versus Continuous Accumulations}

If the potential exists for a type of growth profile to induce high levels of dependency into the Arrington-style of assembly, then the possibility must be considered that the same profile, generated through another means, could do the same. A key difference between conventional and continuous accumulations is the type of growth available. Conventional accumulations are discrete, and it is generally assumed that, once delineated, the field outlines do not substantially change. Continuous accumulations can be areally extensive and have varying well productivities. This situation can lead to sweet spots being developed over small areas, upon which the initial problems can be solved with respect to the best well-drilling, completion, and production design. Once refined, these techniques allow for development of less productive areas within the continuous accumulation and lead to a growth in the overall areal extent of the accumulation. Reserves then grow in proportion to the expanding size of the developed acreage, and there is the potential for extensive growth for long periods of time. Although the mechanism is different from how a conventional field grows, the reserve-growth profile displayed by these two different types of fields will be similar. Figure 22 is an example of a continuous oil field in Texas displaying the sort of reserve-growth profile in conventional fields following the stable-inventory profile. The primary difference between this area and a conventional accumulation, such as South Belridge field in the San Joaquin Basin of California, is that the area of the continuous Texas oil field continues to grow in step with its cumulative production. South-Belridge, in contrast, has been relatively static in terms of the field's areal extent. 


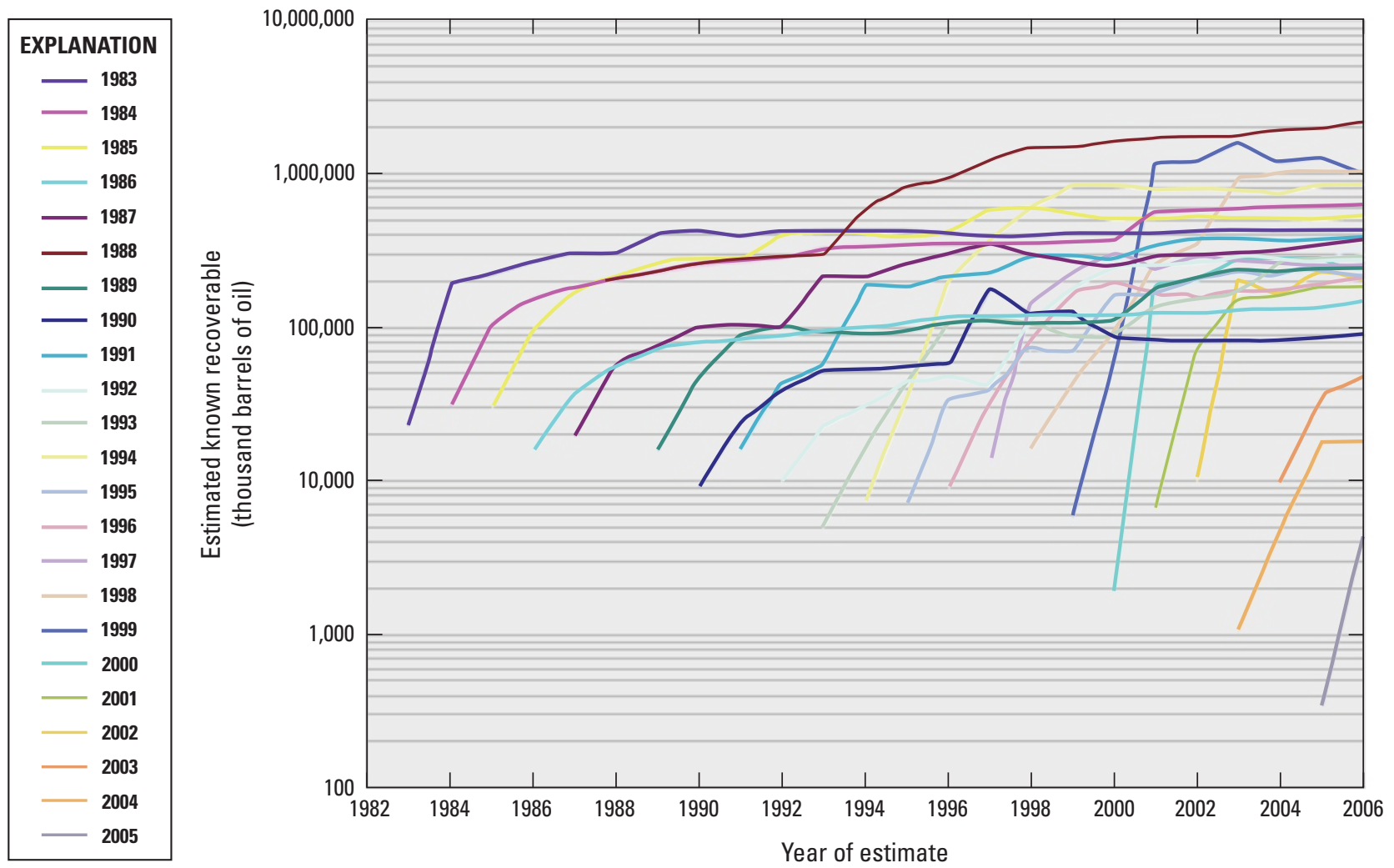

Figure 19. Discovery-year groups with early histories of estimated ultimate recovery through time in U.S. conventional onshore and State waters.

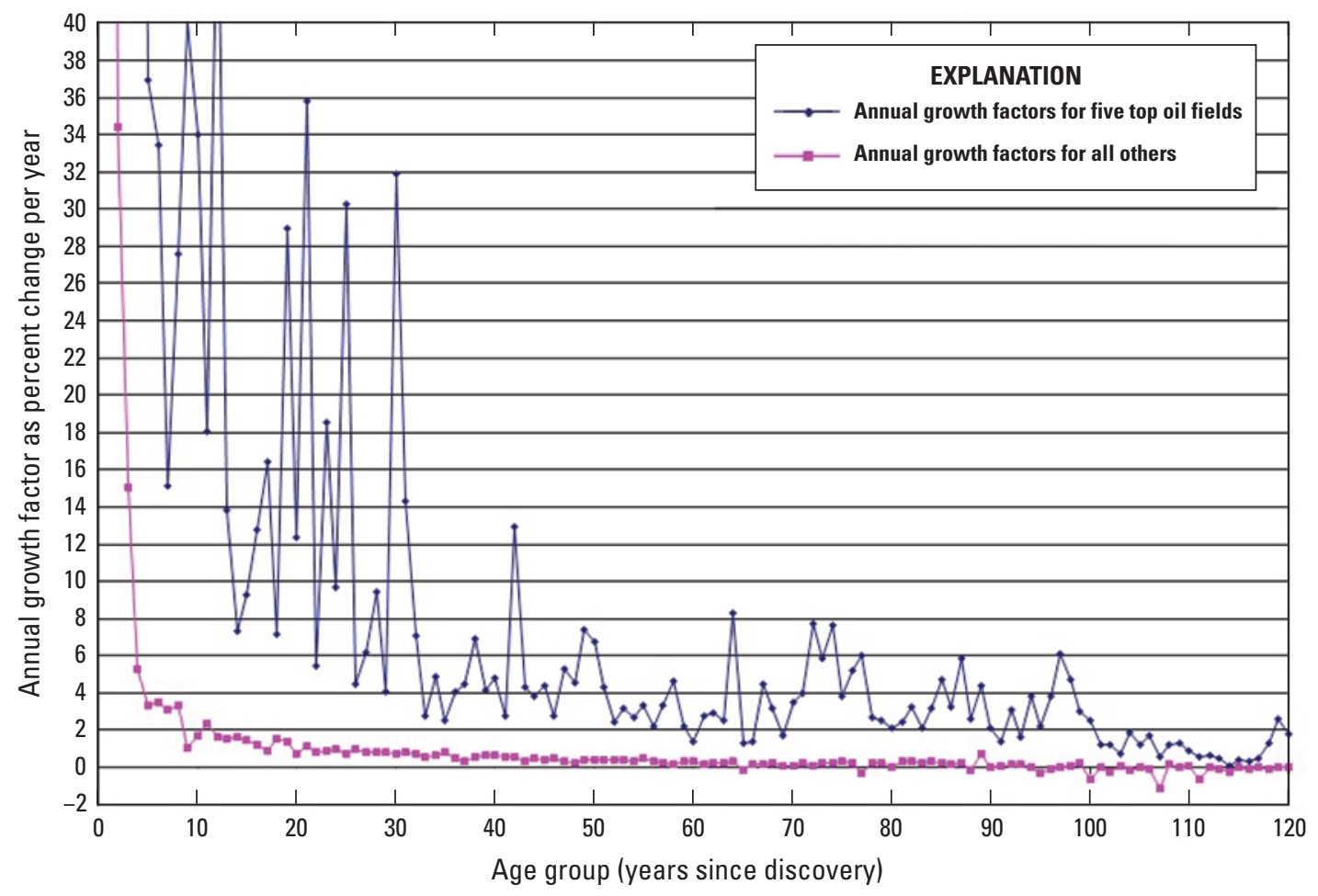

Figure 20. Annual growth factors for top five oil fields in each age-group pair versus all others. 


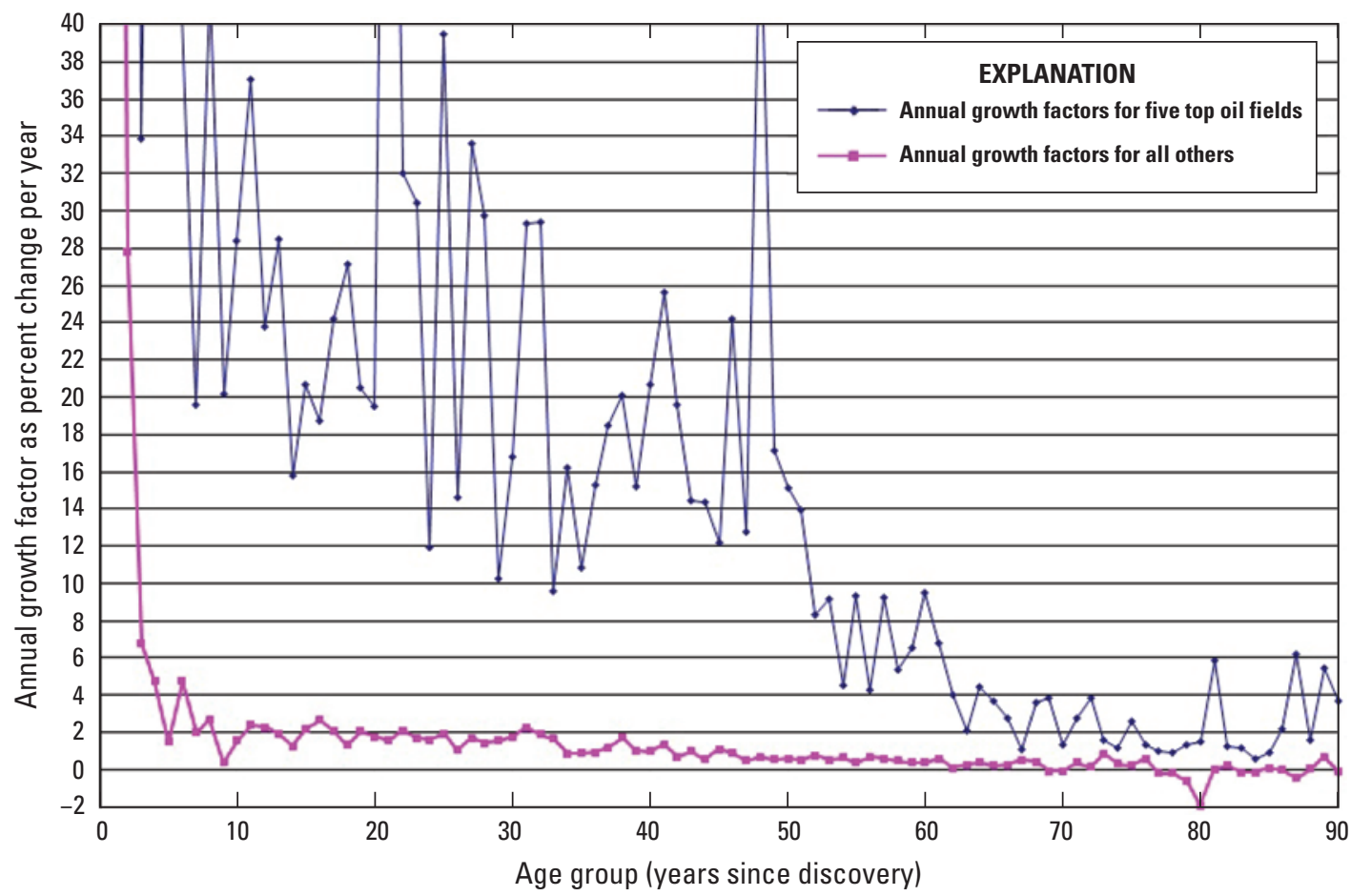

Figure 21. Annual growth factors for top five gas fields in each age-group pair versus all others.

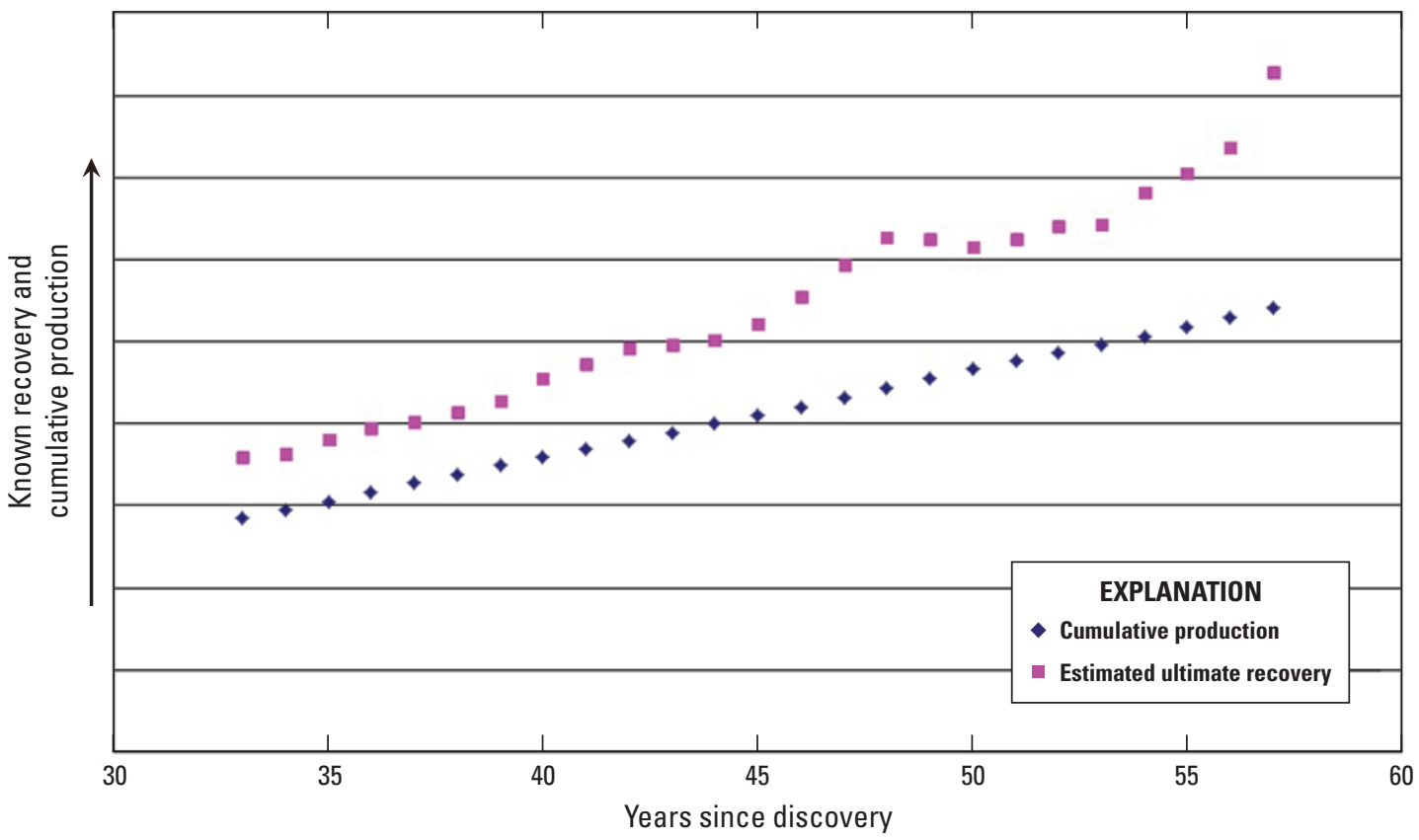

Figure 22. Example of consistent reserve growth in an actual billion-barrel oil field in Texas. 
Continuous accumulations are recognized as being geologically distinct from conventional accumulations and are removed from the field-level data prior to the construction of discovery tables or any other reserve-growth calculations. If not removed they would induce the same dependency effects that a stable-inventory conventional field does.

\section{Discussion}

To a large extent, analysis of reserve growth is dependent on the timing of the analysis, for example, (1) the status of existing data, (2) when the fields were discovered in relation to when a key technology was invented and applied, and (3) the effect of the upward trend in real oil prices that began at the end of the 1960s on the economics of exploration and development. Snapshots of reserve growth across decades could lead to varying conclusions and assumptions.

Questions about the basic assumptions of reserve growth were already being discussed in the literature within a few years of the Attanasi and Root (1994) study; the best overall summary was by Morehouse (1997). Other concerns included the lack of age correlation of certain fields (Tennyson, 2005), the skewed distribution of reserve growth results (Grace, 2006), a single-sentence description of the stable-inventory profile (Sem and Ellerman, 1999), and a proposal to concentrate on the geologic characteristics of the fields involved (Stanley, 2001). Individually these concerns were insufficient to justify fundamental modifications of what appears to be a reasonable and time-tested statistical method to estimate reserve growth. Woven into a greater context and tested against a dataset of similar scope and more recent data than that used in the Attanasi and Root (1994) study, these assumptions of reasonableness may not apply.

\section{General Behavior of Arrington-Style Assemblies}

Attanasi and Root (1994) recognized several important components of reserve growth such as the outliers within the data and the idea that growth was now continuing substantially beyond what once was a perceived limit on the time span available for growth. Attanasi and Root (1994) also used the results of the cumulative growth curve from two different datasets (one including outliers and the other excluding them) as a measure of difference between groups, which was apparently accepted by Morehouse (1997) as a way to measure difference in growth between groups and was continued by Verma and others (2001).

Because Arrington (1960) placed limitations on the statistical nature of his type of assembly, particularly in relation to the application of the resulting function, a few logical questions could be raised. For example, a reasonable assumption about any function designed to quantify reserve growth is that a reduction in volumetric reserve growth should correspond with a reduction in any resulting function's results. The Arrington-style methods, as a combination of volumetric and percentage change, might not react as expected to changes within the data.

Table 4 is an example of an Arrington-style assembly utilizing five hypothetical fields, labeled A through E. The AGF resulting from this combination of five fields is 1.0426. Table 5 is the same example with field A, which is the third largest percentage growing field and the largest growing field volumetrically, removed from the calculation. The AGF for this combination of four fields is 1.0969 ; thus 66 percent of the gross volumetric growth is removed from this hypothetical age-group pair, and the resulting AGF becomes 5 percent higher. This is not necessarily a common result, but with the high level of dependency on a single field or small number of fields, it is a reasonable and possible outcome. A plot using table 2 as a hypothetical AGF string for an Arrington-style assembly and the resulting 5-percent increase to the AGF in year-slice 16 results in the cumulative curve for the entire string as demonstrated in figure 23. The effect of a single 5-percent increase to the AGF in age-group 16, as shown in figure 23, illustrates how such an increase in a single AGF affects the cumulative curve from that point in time onward. For the same amount of change, the effect will be larger or smaller based on its distance from the start of the cumulative

Table 4. Example of an annual growth factor calculation that includes all fields.

\begin{tabular}{lrrrrr}
\hline Field name & $\begin{array}{c}\text { Known recovery } \\
\text { year } \mathbf{5}\end{array}$ & $\begin{array}{c}\text { Known recovery } \\
\text { year } \mathbf{6}\end{array}$ & $\begin{array}{c}\text { Percent } \\
\text { change }\end{array}$ & $\begin{array}{c}\text { Volume } \\
\text { change }\end{array}$ & $\begin{array}{c}\text { Percent } \\
\text { of gross growth }\end{array}$ \\
\hline $\mathrm{A}$ & $3,000,000$ & $3,100,000$ & $3.33 \%$ & 100,000 & $66.49 \%$ \\
$\mathrm{~B}$ & 5,000 & 5,100 & $2.00 \%$ & 100 & $0.07 \%$ \\
$\mathrm{C}$ & 500,000 & 550,000 & $10.00 \%$ & 50,000 & $33.24 \%$ \\
$\mathrm{D}$ & 10,000 & 9,500 & $-5.00 \%$ & -500 & \\
$\mathrm{E}$ & 200 & 500 & $150.00 \%$ & 300 & $0.20 \%$ \\
\hline Totals & $3,515,200$ & $3,665,100$ & $4.26 \%$ & 149,900 & $100.00 \%$ \\
\hline
\end{tabular}


Table 5. Example of an annual growth factor with a single field removed from the calculation.

\begin{tabular}{lrrrrr}
\hline Field name & $\begin{array}{c}\text { Known recovery } \\
\text { year } \mathbf{5}\end{array}$ & $\begin{array}{c}\text { Known recovery } \\
\text { year } \mathbf{6}\end{array}$ & $\begin{array}{c}\text { Percent } \\
\text { change }\end{array}$ & $\begin{array}{c}\text { Volume } \\
\text { change }\end{array}$ & $\begin{array}{c}\text { Percent } \\
\text { of gross growth }\end{array}$ \\
\hline $\mathrm{A}$ & & & & & \\
$\mathrm{B}$ & 5,000 & 5,100 & $2.00 \%$ & 100 & $0.07 \%$ \\
$\mathrm{C}$ & 500,000 & 550,000 & $10.00 \%$ & 50,000 & $33.24 \%$ \\
$\mathrm{D}$ & 10,000 & 9,500 & $-5.00 \%$ & -500 & \\
$\mathrm{E}$ & 200 & 500 & $150.00 \%$ & 300 & $0.20 \%$ \\
\hline Totals & 515,200 & 565,100 & $9.69 \%$ & 49,900 & $33.51 \%$ \\
\hline
\end{tabular}

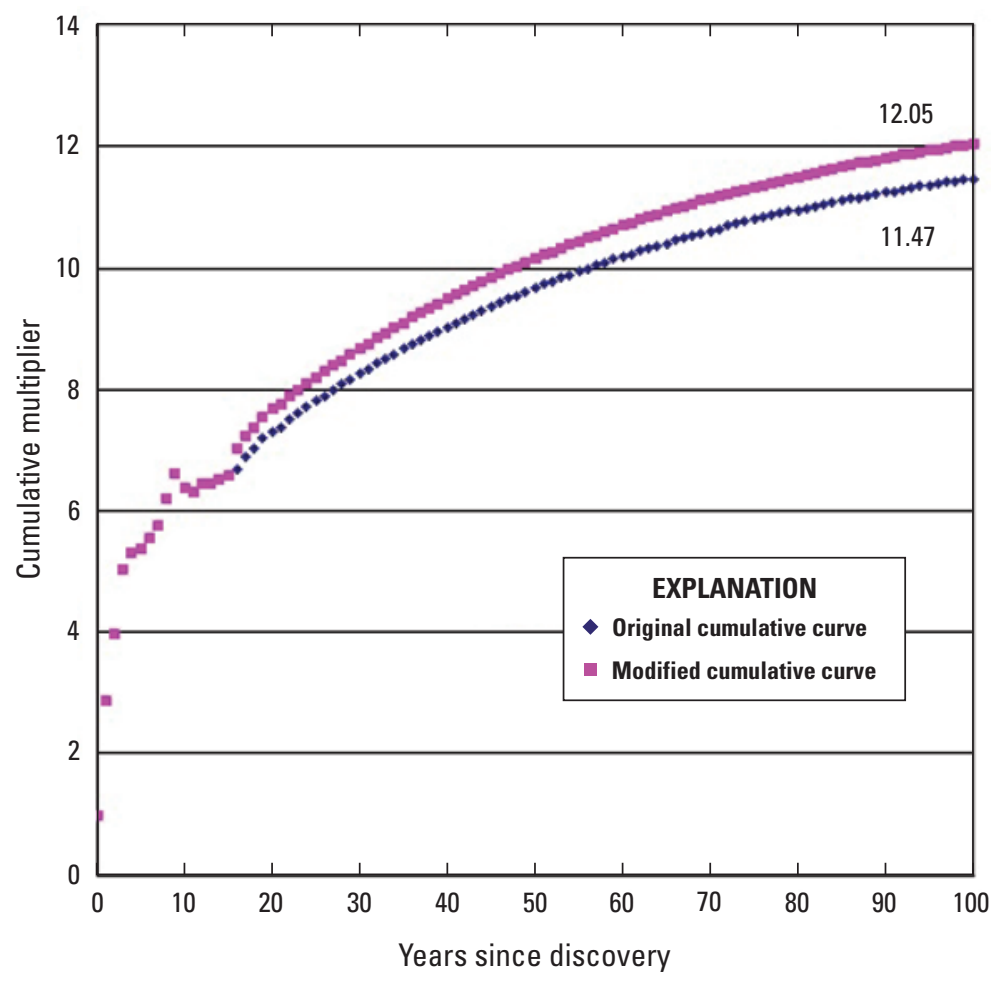

Figure 23. Differences in cumulative growth curve results based on a single annual growth factor change. 
curve; for this example, the resulting change is a 0.58 increase. If this field had the same dominating effect on other age-group pairs under the same conditions, it would be reasonable to speculate that by removing this high-dependency and highvolume reserve-growth field from the data the AGF could possibly increase across a number of age-group pairs, and the cumulative result might increase even more.

The Arrington-style of assembly has other possible dependencies within it. One of Arrington's (1960) stated limitations is that no resulting rate of growth could be applied to other datasets or to an individual field. This may also apply to exactly the same growth and shrinkage if the static fields, those within each age-group pair that neither grow nor shrink and are therefore net neutral to any reserve growth volume changes, are removed and a growth function calculated. Their estimated known recoverable is included in the denominator of each age-group pair. Excluding this group of fields would therefore not change the numerator but would certainly decrease the denominator and by extension increase AGFs in all age-group pairs. Figure 24 is a real discovery group example of this type of effect. Any and all fields that did not change in a given year were excluded from the AGF calculation, and these AGFs were then multiplied together to form a cumulative curve to compare with the other examples. The cumulative result in this case reaches an expected value of 11.02 within 24 years.

The uncertain behavior of these derivative products of the Arrington-style assembly warrants caution in their use. The function is not only limited to the fields in any aggregation of data but is dependent on the exact and unique combination

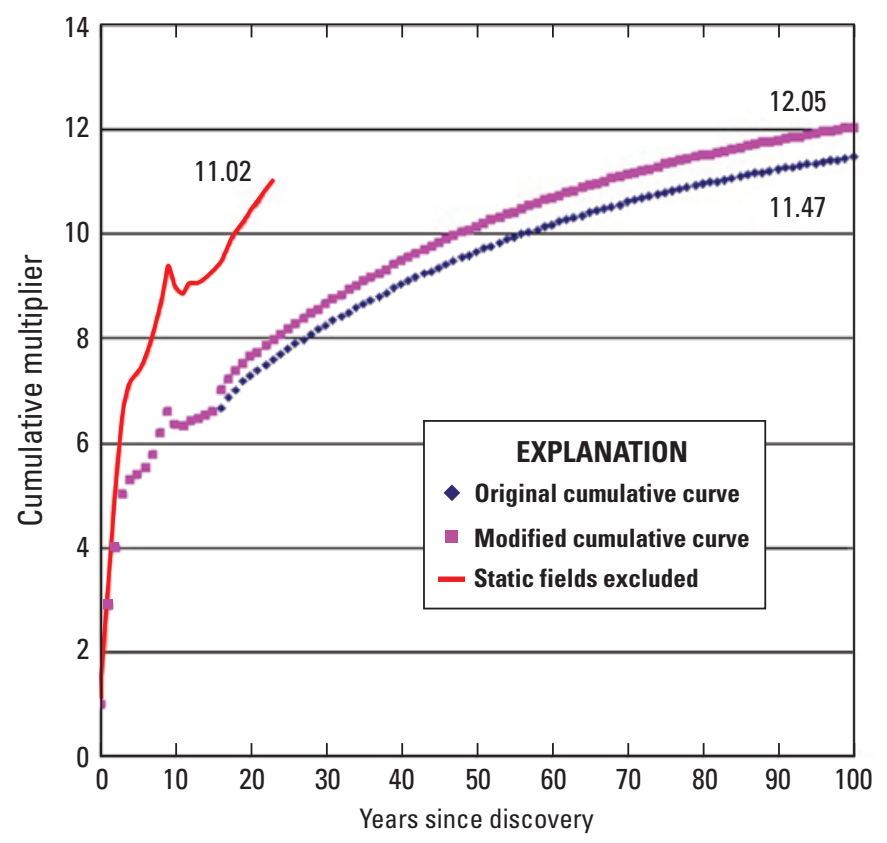

Figure 24. Differences in cumulative growth curve results based on the removal of all fields with no changes in reserve growth in that age-group pair. Excluded cumulative growth line terminated early for reasons of scale. only for that dataset. The same amount of growth in any aggregation, identical in volumetric measure, can lead to completely different results in either a positive or negative direction based solely on the inclusion or exclusion of fields that show no growth or shrinkage whatsoever.

Arrington (1960) categorized his method as a running rate of growth for an exact combination of fields and issued some general warnings on its use for good reason. One of his assumptions - more fields would yield a better result — might not be reasonable if the addition or subtraction of a single field can change the results randomly.

\section{Reserve-Growth Outliers}

Attanasi and Root (1994) used a cumulative curve to demonstrate differences between common and outlier fields and also noted their respective contributions to the overall growth in the United States. These outliers were characterized as large heavy-oil fields and old low-permeability gas fields whose reserve growth was six times faster than the common fields; the common fields were all of those remaining after the outliers were removed. Attanasi and Root's (1994) analysis was based on the Oil and Gas Integrated Field File (OGIFF) provided by the EIA, and the information in this study relies on the NRG Associates (2008) database. The term "outlier" in this study is used to describe oil or gas fields that have an effect on the overall reserve growth out of proportion to their known recoverable size. The count of outliers in the Attanasi and Root (1994) study numbered 7,492 of 18,529 oilfields (40 percent) and 4,784 of 14,851 gas fields ( 32 percent). The results of this study indicate that the concentration of outliers might be much smaller than that envisioned by Attanasi and Root (1994).

To calculate the outliers for the present study, the NRG Associates (2008) database was divided into two groups. All oil and gas fields discovered after 1982 were separated from the older fields to quantify growth of the newer fields separately from the older fields.

Oil fields discovered from 1982 to 2006 totaled 974 with 1.7 billion barrels of known recoverable oil, and the 8,300 oil fields discovered prior to 1982 grew 22.5 billion barrels in known recoverable oil between 1982 and 2006. A total of 887 gas fields were discovered from 1982 to 2006 with a known recoverable gas of 21.7 trillion cubic feet of gas (TCFG) in 2006, and the 4,032 fields discovered prior to 1982 grew 166.0 TCFG between 1982 and 2006. The newer oil fields are approximately 7 percent of the total known recoverable in 2006, and the newer gas fields are approximately 11.5 percent of the total known recoverable in 2006.

Of all oil fields discovered prior to 1982, 256 (3.1 percent) accounted for 75 percent of gross oil reserve growth between 1982 and 2006. Of those fields, 191 also had a PRR $>0.75$ and contained 63 percent of all gross oil reserve growth discovered between 1982 and 2006.

Of all gas fields discovered prior to 1982, 228 (5.6 percent) accounted for 75 percent of gross gas reserve growth 
between 1982 and 2006. Of those fields, 132 also had a PRR $>0.75$ and contained 42 percent of all gross reserve growth discovered between 1982 and 2006.

The Attanasi and Root (1994) outliers were determined by comparing a field's growth performance against the behavior of the group. The outlier fields in the summary above were determined by the size of their volumetric contribution to overall reserve growth contained within the NRG Associates (2008) dataset. The difference between these two methods of calculating outliers indicates that volumetric reserve growth is a much more stringent criterion than measuring variation from group behavior. Understanding this concentration of effective reserve growth in so few fields is critical to understanding reserve growth in general.

\section{Commonness of Reserve Growth}

Another assumption of reserve growth is that it is a common phenomenon that involves oil and gas fields of all types over extended periods of time. However, based on the near volumetric balance between growing fields and shrinking fields in any particular age-group pair, the reality is that reserve growth relies on a minority of fields to sustain the growth for the entire group. This is readily apparent from an examination of figure 19, which shows that there is growth for a short period of time after discovery; in a relatively few years there is already a reliance on a minority of the fields for continued growth of the entire group. A small number of fields, many clearly displaying the stable-inventory profile, have been responsible for the large amounts of reserve growth seen in the United States over the past 25 years. Rather than a common characteristic, effective reserve growth in terms of substantial volumetric change is actually the minority effect of a few fields. Once these types of fields are excluded from the data, the true time span of common reserve growth becomes more obvious; hence, it could be argued that newly discovered fields are more likely to follow that general time span and to more accurately represent the size of reserve growth than one predicated on high dependency on a small minority of fields.

It would be reasonable to suggest that the profile of stable inventory is not only the signature of reserve growth but has single handedly created the assumption of long-term and common reserve growth. Following from this reasoning is the idea that a better understanding of reserve growth would involve localizing attention on the fields displaying a stable-inventory profile. An examination of these fields would reveal not only how they acquired this particular profile but how long they can maintain it. If an assessment of reserve growth is based on the infinite "tail" of an Arrington-style assembly, it leads to the conclusion that reserve growth is a process that could continue for centuries. In fact, when the final field upon which this infinite-appearing function is built achieves its geologic limit, the ability to project infinite-appearing growth in that group ends with it. Some fields can maintain this stable-inventory profile for multiple decades but many more are shrinking and in danger of becoming economically challenged within 70 years for oil fields and 50 years for gas fields.

\section{Age Correlation of Reserve Growth}

Another common assumption is that reserve growth is age-based, with significant increases more common early in a field's life than as the field ages. Although this assumption does appear to operate in a general sense early in a field's life, it does not appear to extend beyond approximately a decade after the start of production. At that point, the field-level growth of the majority of fields has decreased significantly, leaving behind only a small minority of fields exhibiting the stable-inventory profile. Part of this assumption relates to the volumetric/percentage form of measure used while a particular field or combination of fields grows, or shrinks, when compared to others. The PRR is age-independent and created in part to deal with exactly this type of ambiguity. The PRR also has the capacity to find the timing of the change of the reservegrowth profile from a stable inventory to a field that no longer replaces its production. This is a critical difference because it signals the possible beginning of the end for reserve growth in a particular field, and the factors causing it may not be age dependent.

\section{The Lifespan of Reserve Growth}

The concept of reserve growth in fields has been well established in various individual field-level analysis and field-grouping studies at both the domestic and international levels. For purposes of discussion and convenience, the study of reserve growth prior to Attanasi and Root (1994) will be referred to as the early era of the study of reserve growth and everything after the publication of their study will be considered the modern era. This division is important because of the changing nature of reserve-growth concepts with respect to time. The Attanasi and Root (1994) study is used as the dividing line because within it are questions that continue to this day.

Upon examining the modern literature, it becomes apparent that reserve growth is accepted as a common and long-lived phenomenon. Functions formulated from various datasets are used to project growth as far into the future as their creators might wish. It is noteworthy that some studies have applied functions over three centuries of growth in an expectation of near-infinite growth. However, studies in the early era estimated reserve growth in more finite terms. Arrington's (1960) original example terminated AGFs within 30 years, and Hubbert's (1967) method had an assigned asymptote that approached a given CGF within 50 years. This same type of limit was used by Mast and Dingler (1975) of the USGS for inferred reserves calculations. Reserve-growth functions were terminated by design.

The difference between short-term reserve growth (approximated at 50 years) and long-term growth dominated 
by fields displaying the stable-inventory profile is evident from the breakdowns of age-group pairs previously discussed in the Reserve-Growth Outliers section of this study. It is also reasonable to infer that a stable profile might not exist in other groups because of the "too early for the technology" nature of these particular fields. If the fields in question had been developed initially using the same technology they are subjected to today, their stable-inventory profile might not survive a 50 -year lifespan any better than other fields. Because of this delayed development and the resulting outsized reservegrowth effect, any method to assess their potential must be more detailed than a general statistical study.

Other studies have noted the uneven nature of reserve growth within their area of interest. If reserve growth in these areas is driven by a small number of fields creating a substantial part or a majority of the reserve growth, it would not be unexpected. Key indicators are (1) fields discovered prior to modern technology in general and a technology specifically necessary for that field's development, (2) fields with a delayed access to modern technology, (3) improper or early application of a technology later corrected or improved, (4) extensive secondary pools available after primary reservoir depletion, and (5) lack of a governing or regulatory environment conducive to oil and gas development.

Early methods of estimating reserve growth had time and growth limitations as part of their design. Arrington (1960), for example, could use a French curve to create an AGF of 1.0 at a specific point, and Hubbert (1967) constructed equations with built-in asymptotes. The fields used in their studies were younger, and in some cases the stable-inventory profiles had not been established in advance of the widespread use of a particular technology. Without a study of individual field data at this early stage, the early indicators of anomalous fields would not necessarily have revealed themselves as many modern technologies were not common industry practice in this approximate time frame.

By the time the Attanasi and Root (1994) study was published, the accumulated oil and gas field information had grown substantially in length and scope, covering all fieldlevel data available to the EIA in the OGIFF file. This added substantial amounts of detailed data to any Arrington-style assembly, and based on Arrington's (1960) own statement, "it follows that the greater number of statistics used, the greater is the probability of final accuracy," should lead to better estimates. However, the additional data in Attanasi and Root (1994) also began to reveal a higher performing subgroup within the overall data. A cumulative curve was constructed and used to compare this subgroup to the data as a whole, thus creating both a comparative metric and the perception that reserve growth did not have the natural limitations as practiced by Arrington (1960) and Hubbert (1967). These ideas propagated within the general literature from that point in time forward.

Beliveau and Baker (2003), for example, stated "Reserve growth occurs in all fields, but it is more pronounced in lower quality reservoirs such as heavy oil, tight gas, or other marginal resources," which implied that if reserve growth occurs in all fields, it is therefore significant on a general basis. They also incorporated the idea of a cumulative curve growth function as a means of comparison between the U.S. fields and the Western Canadian Sedimentary Basin fields.

Verma (2007) used seven different cumulative growth curves on a single chart to compare growth among widely different areas. Baker and Jong (2004) stated that "A particularly significant finding from Attanasi and Root's study is that the multiple of initial reserves estimate does not plateau after time but continues to gradually increase..." A natural extension of these assumptions arrived in the form of the "Inventory of Federal Onshore Oil and Natural Gas Resources and Restrictions to Their Development," appendix 7 of the EPCA Phase III inventory (U.S. Departments of Interior, Agriculture, and Energy, 2008). Appendix 7 of EPCA dealt with the initial estimates of remaining proved ultimate recovery growth included in the report, and several examples of the previously mentioned issues are demonstrated such as (1) there is no mention of reservoir differentiation with respect to continuous or conventional accumulations, (2) a type of cumulative growth graph forecasts reserve growth across three centuries from initial discovery and was the primary means of comparison and calculation, and (3) data anomalies (outliers) were accepted "as-is." This report is the perfectly logical extension of what was implied from the prior 15 years in concepts related to reserve growth.

\section{Implications}

The generally assumed pattern of reserve growth when quantified using an Arrington-style of assembly is strongly influenced by outliers included in the data. Outliers, for the purposes of this discussion, are fields that produce reserve growth of sufficient volumes to not only offset the cumulative reserve shrinkage from all other fields of similar age but create enough additional growth to create the impression that the entire group is growing. These outliers, a majority of which display the stable-inventory profile, have a much greater impact on the aggregate data than expected. As the dependence on fewer fields (or even one) dominates the resulting AGF calculation, the likelihood of that calculation no longer behaving in a predictable manner increases. A single change in a single AGF calculation resulting from a single field is more than enough to change the outcome of the entire cumulative growth curve as demonstrated in figure 23 . As the stable-inventory profile ceases in one field, the growth displayed by the group will become more dependent upon the stable-inventory fields remaining. This cascading effect will continue down to the final field displaying a stable-inventory profile, and group reserve growth will terminate abruptly with that field.

Based on the volumetric influence of these outliers and their minority presence within the data, it is reasonable to 
ask if these outliers are in fact the only reserve growth that needs to be studied. This would appear to be a reasonable approach considering that only 3.1 percent of the oil fields and 5.6 percent of the gas fields account for 75 percent of the gross reserve growth in the United States for the past quarter century.

Once the perspective of reserve growth as a profile rather than a volumetric or percentage calculation has been established, other assumptions about reserve growth such as an age correlation for growth and its overall commonality may not hold up to further scrutiny. The stable-inventory profile of growth is tied to not just development over a field's lifetime but the ability to maintain a steady pace of development. In the examples of Midway Sunset and Mount Poso oil fields, this development has continued for several decades. The technological improvements upon which that growth was based will not occur in future oil fields at the same temporal distance from discovery but will be applied earlier and over shorter timeframes. This precludes two assumptions from being applied to future estimates of reserve growth: (1) the future will look like the past and (2) the application of this development to smaller fields (based on the assumption that larger fields tend to be found first) will not yield the same volumetric gains as their larger and older precursors. The large field size of the early discoveries allows large-scale applications of costlier technologies and the economies of scale that come with it. Applying that same technology on an oil field 1/1,000 the size would be volumetrically insignificant.

The concept of reserve growth is that it is pervasive for all fields, basins, provinces, or countries. The concept of "effective reserve growth" (demonstrated by the outliers), on the other hand, may not be so broadly applicable. The data indicate that most fields grow to their recoverable size early in their lives, as shown in figure 19. As development continues, uncertainties with respect to continued growth are minimized as well as estimates of ultimate field size. Within this overall growth pattern, and providing the main volumetric basis for reserve growth, are the effective reserve-growth fields. It is expected that these fields, small in number, will drive the growth profile of any group within which they are included. Exploration within the data using a field-size measure and the PRR could find effective reserve-growth fields and allow them to be extracted for further study upon which a more accurate forecast of reserve growth could be built.

The presumption of how long reserve growth could continue has changed since Arrington published his running rate of growth method (Arrington, 1960). Early methods like his and that of Hubbert (1967) were limited by design, and the effect of technological advancement was not discernible within the available data. There was no presumption at that point in time of seemingly endless growth.

The perspective of generally short-term reserve growth changed with the publication of the Attanasi and Root (1994) study. The primary effect was that the sequential length of AGFs greater than 1.0 were extended as far as the available data would permit and could now be configured into a cumulative growth curve. This cumulative curve (1) did not appear to have a natural asymptote, and successive users of this technique arrived at the previously mentioned (and logically expected) three centuries of expected reserve growth and (2) seemed like a reasonable comparative measure at the time.

The precursor to the "effective reserve growth" fields in this study were identified as "outliers" (old, large California oil fields and low-permeability gas fields) and quantified. Identified in this study as a much smaller subset, these stableinventory-profile fields creating "effective reserve growth" were already dominating any Arrington-style method of data assembly. These fields, producing reserve-growth oil and natural gas at rates equal to their actual production, out of sequence with their actual age when compared to other fields, were creating an effect far larger than their numbers would otherwise suggest.

Long-term reserve growth is completely dependent on the mix of stable-inventory fields included in a group and will continue as long as there are fields maintaining the stableinventory profile. Reserve growth ultimately ceases when the final field within any given group changes from having an inventory profile to a PRR approaching 0 . Based on oil and gas fields in the United States, this is the most common result for a majority of the fields producing approximately five to seven decades. It should be noted that the stable-inventory profile also resembles the profile of continuous accumulations as they expand in area during development. Without careful examination of the applicable geologic considerations, the unconventional fields could also cause the illusion of nearinfinite growth if included in any conventional field-growth analysis.

This study has shown that calculations of the AGF that compose the cumulative growth curve have the ability, under certain conditions, to fluctuate results arbitrarily. Whether the problem is the reduction in growth causing increases in Arrington-style functions or no changes in growth causing increases or decreases in Arrington-style functions, the level and unpredictability of these fluctuations is substantial enough to call into question not only the value of the AGF calculation but also that of any derivative product. This study does not discount the possibility that the AGF calculation used strictly as a nonlinear, best-fit regression of Arrington's (1960) original "running rates of decline" problem might have some value if the underlying data and limitations of the method are well understood.

\section{Summary}

Reserve growth has been and will continue to be a critical component of conventional resource assessments. Since the release of the USGS 2000 world assessment (U.S. Geological Survey World Energy Assessment Team, 2000) and through 2009 , volumetric conventional oil and natural gas field reserve 
growth has outpaced new oil and gas discoveries by approximately $3: 1$ and 2:1, respectively.

Based on this examination of reserve growth in the NRG Associates (2008) database, this study shows that though many fields grow, far fewer than suspected are providing effective reserve growth. These fields are of a specific type of production and growth profile and are of such size that they can generate impressions of overall and long-lasting growth even when combined with tens, hundreds, or thousands of others. The nature of the Arrington-style assembly and its derivative products only reinforce these impressions and provide no comparative measures among groups of fields.

These implications indicate that including a focused geologic and engineering examination at the field level will improve assessments of future reserve growth. The large volumetric contribution of reserve growth from a small number of fields makes this time- and labor-intensive examination possible. Statistical aggregation methods based on the Arringtonstyle of assembly should be used with great care and a high level of understanding of the follow-on effects when dealing with the highly skewed distribution of volumetric reserve growth in fields.

\section{Acknowledgments}

I would like to thank Lauri Burke and Ronald Charpentier for their review of this manuscript. I wish to thank Mahendra Verma for engineering-centric conversations on past mechanisms and processes of reserve growth, Lynn Tennyson for never forgetting to mention that the San Joaquin Basin really was different and having the information to prove it, and James Schmoker and Tim Klett for demonstrating how interesting this topic was in the first place.

\section{References Cited}

Arps, J.J., and Roberts, T.G., 1958, Economics of drilling for Cretaceous oil on east flank of Denver-Julesburg Basin: American Association of Petroleum Geologists Bulletin, v. 42 , no. 11 , p. $2549-2566$.

Arrington, J.R., 1960, Predicting the size of crude reserves is key to evaluating exploration programs: Oil \& Gas Journal, v. 58 , no. 9 (19 February), p. 130-134.

Attanasi, E.D., and Root, D.H., 1994, The enigma of oil and gas field growth: American Association of Petroleum Geologists Bulletin, v. 78, no. 3, p. 321-332.
Baker, R.O., and Jong, E.W.S., 2004, Understanding the enigma of reserves growth: The whys: Canadian International Petroleum Conference Paper 2004-272.

Beliveau, D., and Baker, R., 2003, Reserves growth: Enigma, expectation or fact?: Society of Petroleum Engineers Paper SPE 84144, SPE Annual Technical Conference and Exhibition, Denver, Colorado, 5-8 October, $10 \mathrm{p}$.

Forbes, K.F., and Zampelli, E.M., 2009, Modeling the growth in gas reserves from known fields: The Energy Journal, Special Issue, World Natural Gas Markets and Trade: A Multi-Modeling Perspective, p. 201-213.

Gautier, D.L., Dolton, G.L., Takahashi, K.I., and Varnes, K.L., eds., 1996, 1995 National assessment of United States oil and gas resources - Results, methodology, and supporting data: U.S. Geological Survey Digital Data Series DDS-30, release 2, one CD-ROM.

Grace, J.D., 2006, A closer look at field reserve growth: Science, engineering, or just money: Reservoir characterization: Integrating technology and business practices: 26th Annual, p. 1-22, DOI: 10.5724/gcs.06.26.0001.

Hubbert, M.K., 1967, Degree of advancement of petroleum exploration in United States: American Association of Petroleum Geologists Bulletin, v. 51, no. 11, p. 2207-2227.

Klett, T.R., 2003, Graphical comparison of reserve-growth models for conventional oil and gas accumulations, in Dyman, T.S., Schmoker, J.W., and Verma, M.K., eds., Geologic, engineering, and assessment studies of reserve growth: U.S. Geological Survey Bulletin 2172-F, 63 p., http://geology.cr.usgs.gov/pub/bulletins/b2172-f/.

Mast, R.F., and Dingler, J., 1975, Estimates of inferred and indicated reserves for the United States by States, in Miller, B.M., Thomson, H.L., Dolton, G.L., Coury, A.B., Hendricks, T.A., Lennartz, F.A., Powers, R.B., Sable, E.G., and Varnes, K.L., eds., Geological estimates of undiscovered recoverable oil and gas resources in the United States: U.S. Geological Survey Circular 725, p. 73-78.

Morehouse, D.F., 1997, The intricate puzzle of oil and gas "reserve growth": Energy Information Administration, Natural Gas Monthly, July 1997, 20 p.

NRG Associates, 2008 [includes data current as of December 2006], The significant oil and gas fields of the United States: NRG Associates, Inc.; database available from NRG Associates, Inc., P.O. Box 1655, Colorado Springs, CO 80901, U.S.A. 
Schmoker, J.W., and Klett, T.R., 2000, Estimating potential reserve growth of known (discovered) fields: A component of the USGS world petroleum assessment 2000, in U.S. Geological Survey World Energy Assessment Team, eds., U.S. Geological Survey world petroleum assessment 2000: U.S. Geological Survey Digital Data Series DDS-60, 4 CD-ROMs, $20 \mathrm{p}$.

Sem, T., and Ellerman, A.D., 1999, North Sea oil reserve appreciation, production and depletion: Cambridge, Massachusetts Institute of Technology, Center for Energy and Environmental Policy Research Paper MIT-CEEPR 99-011 WP, $39 \mathrm{p}$.

Stanley, R.G, 2001, Geologic constraints on the upper limits of reserve growth: U.S. Geological Survey Open-File Report 01-265, $7 \mathrm{p}$.

Tennyson, M.E., 2005, Growth history of oil reserves in major California oil fields during the twentieth century, in Dyman, T.S., Schmoker, J.W., and Verma, M.K., eds., Geologic, engineering, and assessment studies of reserve growth: U.S. Geological Survey Bulletin 2172-H, 15 p., http://geology.cr.usgs.gov/pub/bulletins/b2172-h/.

U.S. Departments of Interior, Agriculture, and Energy, 2008, Inventory of onshore Federal oil and natural gas resources and restrictions to their development, Phase III inventoryOnshore United States: Bureau of Land Management Web site, appendix 7, p. 329-340, http://www.blm.gov/wo/st/en/ prog/energy/oil_and_gas/EPCA_III.html.

U.S. Geological Survey World Energy Assessment Team, 2000, U.S. Geological Survey world petroleum assessment 2000: U.S. Geological Survey Digital Data Series DDS-60, 4 CD-ROMs.

Verma, M.K., 2005, A new reserve growth model for United States oil and gas fields: Natural Resources Research, v. 14, no. 2 , p. $77-89$.

Verma, M.K., 2007, The reality of reserve growth: Geo ExPro, October 2007, p. 34-35.

Verma, M.K., and Henry, M.E., 2004, Historical and potential reserve growth in oil and gas pools in Saskatchewan, in Summary of investigations 2004, v. I: Saskatchewan Geological Survey, Saskatchewan Industry Resources, Miscellaneous Report 2004-4.1, CD-ROM, Paper A-1, 20 p.

Verma, M.K., and Ulmishek, G.F., 2003, Reserve growth in oil fields of West Siberian Basin, Russia: Natural Resources Research, v. 12, no. 2, p. 105-119.

Verma, M.K., Ulmishek, G.F., and Gilbershtein, A.P., 2001, Slower reserve growth rates observed in Volga-Ural Province, Russia: Oil \& Gas Journal, v. 99, no. 9 (26 February), p. 34-44.
Publishing support provided by:

Denver Publishing Service Center

For more information concerning this publication, contact: Center Director, USGS Central Energy Resources Science Center Box 25046, Mail Stop 939

Denver, CO 80225

(303) 236-1647

Or visit the Central Energy Resources Science Center Web site at: http://energy.usgs.gov/ 
$\frac{\mathbb{2}}{8}$

\&̊․․ 